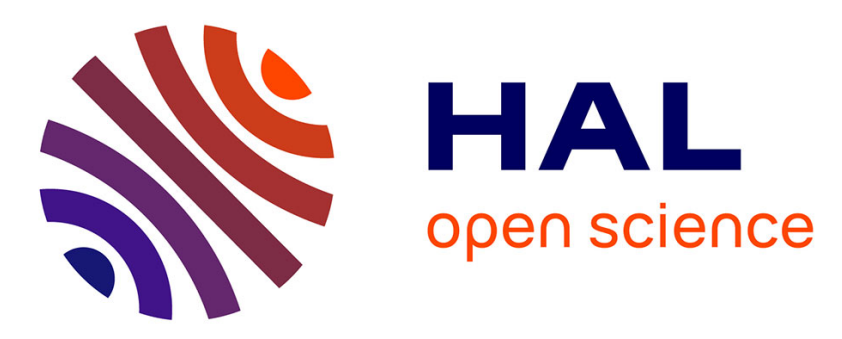

\title{
Neutron/gamma pulse shape discrimination in plastic scintillators: Preparation and characterization of various compositions
}

\author{
Pauline Blanc, Matthieu Hamel, Chrystèle Dehé-Pittance, Licinio Rocha, \\ Robert B. Pansu, Stéphane Normand
}

\section{To cite this version:}

Pauline Blanc, Matthieu Hamel, Chrystèle Dehé-Pittance, Licinio Rocha, Robert B. Pansu, et al.. Neutron/gamma pulse shape discrimination in plastic scintillators: Preparation and characterization of various compositions. Nuclear Instruments and Methods in Physics Research Section A: Accelerators, Spectrometers, Detectors and Associated Equipment, 2014, 750, pp.1-11. 10.1016/j.nima.2014.02.053 . hal-01082176

\section{HAL Id: hal-01082176 https://hal.science/hal-01082176}

Submitted on 26 Mar 2020

HAL is a multi-disciplinary open access archive for the deposit and dissemination of scientific research documents, whether they are published or not. The documents may come from teaching and research institutions in France or abroad, or from public or private research centers.
L'archive ouverte pluridisciplinaire HAL, est destinée au dépôt et à la diffusion de documents scientifiques de niveau recherche, publiés ou non, émanant des établissements d'enseignement et de recherche français ou étrangers, des laboratoires publics ou privés. 


\section{Neutron/gamma pulse shape discrimination in plastic scintillators: 2 preparation and characterization of various compositions}

4 Pauline Blanc, ${ }^{1,2}$ Matthieu Hamel, ${ }^{1, *}$ Chrystèle Dehé-Pittance ${ }^{1}$, Licinio Rocha, ${ }^{1}$ Robert B. Pansu, ${ }^{2}$ and Stéphane Normand ${ }^{1}$

6 1. CEA, LIST, Laboratoire Capteurs et Architectures Électroniques, F-91191 Gif-sur-Yvette, France

2. Laboratoire de Photophysique et Photochimie Supramoléculaires et Macromoléculaires (CNRS UMR 8531), École Normale Supérieure de Cachan, 61 Avenue du Président Wilson, F-94235 Cachan cedex, France

\section{Abstract}

This work deals with the preparation and evaluation of plastic scintillators for neutron/gamma pulse shape discrimination (PSD). We succeeded in developing a plastic scintillator with good neutron/gamma discrimination properties in the range of what is already commercialized. Several combinations of primary and secondary fluorophores were implemented in chemically modified polymers. These scintillators were fully characterized by fluorescence spectroscopy and under neutron irradiation. The materials proved to be stable for up to 5 years without any degradation of PSD properties. They were then classified in terms of their PSD capabilities and light yield. Our best candidate, $28.6 \mathrm{wt} \%$ of primary fluorophore with a small amount of secondary fluorophore, shows promising PSD results and is particularly suited to industrial development, because its preparation does not involve the use of expensive or exotic compounds. Furthermore, even at the highest prepared concentration, high stability over time was observed. As a proof of concept, one sample with dimensions $109 \mathrm{~mm} \varnothing \times 114 \mathrm{~mm}$ height $(\approx 1 \mathrm{~L})$ was prepared.

\section{Keywords}

plastic scintillator; pulse shape discrimination (PSD); neutron detection; fluorescence; scintillation

\section{Introduction}

From the very beginning of neutron detection, pulse shape discrimination (PSD) between neutrons and gamma rays in plastic scintillators remained one of the holy grails of modern physics, as they were widely considered to be indistinguishable. However, in 1960, F. D. Brooks discovered that doping a standard plastic scintillator (e.g., polystyrene $+p$-terphenyl + POPOP) with a so-called "secondary solvent" (herein 4-isopropylbiphenyl) allowed discrimination of fast neutrons from gamma [1]. His "Plastic 77" was later marketed under the trade name NE-150 but was, unfortunately, discarded after physical alterations appeared a few months after production [2]. Since then, several research groups have tried to address this challenge by various means, leading to different levels of success. Their efforts have involved a chemical approach [3], the use of a given geometry that allows gamma rejection [4], and mathematical approaches using smart algorithms that identify the sharp difference existing between neutron and gamma signals [5]. Recently, Zaitseva and co-workers, presumably inspired by previous work from Brooks, developed a new plastic scintillator composed from highly concentrated 2,5-diphenyloxazole (PPO) and a wavelength shifter (optional), 9,10-diphenylanthracene (DPA), in polyvinyltoluene (PVT) [6a,b]. They showed that good PSD was observed only when a given PPO concentration threshold was reached. This new plastic scintillator is currently being sold, most likely with slight modifications from what was originally described, by Eljen Technologies under

\footnotetext{
* Corresponding author. Tel: +33 1690833 25; fax: +331690860 30. E-mail address: $\underline{\text { matthieu.hamel@cea.fr }}$ (please do not send commercial e-mails).
} 
the trade name EJ-299-33 [6c-e][7]. In 2012, Feng et al. proposed for the first time both spectral and pulse shape discrimination in plastic scintillators, with a triplet harvesting system consisting of an iridium complex [8]. In 2006, a French collaborative effort called Neutromania was initiated for developing new plastic scintillators for this purpose, embedding 5 laboratories from 3 cities and gathering physicists and chemists. This project was the foundation for the work that produced the results presented herein. We will see that a general formulation consisting of \{polymer + highly concentrated $1^{\text {st }}$ fluorophore $+2^{\text {nd }}$ fluorophore as wavelength shifter\} can be used to prepare various plastic scintillators. The present paper determines their ability, or inability, to discriminate neutrons from gamma. We present herein our results regarding the preparation and characterization of plastic scintillators with various compositions, displaying good neutron/gamma pulse shape discrimination efficiency in the range of existing discrimination methods.

\section{Experimental}

Encapsulated liquid scintillator BC-501A and plastic scintillator BC-408 were obtained from SaintGobain Crystals and Detectors (Aubervilliers, France). Plastic scintillator EJ-200 was obtained from Eljen Technologies (supplied by Scionix, Bunnix, The Netherlands). Styrene and vinyltoluene monomers were purchased from Sigma-Aldrich and freshly distilled from $\mathrm{CaH}_{2}$ prior to use. 1,4Bis(5-phenyl-2-oxazolyl)benzene (POPOP), 9,10-diphenylanthracene, $p$-vinylbiphenyl, and $p$ terphenyl were also purchased from Sigma-Aldrich. 4-isopropylbiphenyl was purchased from Alfa Aesar. 2,5-Diphenyloxazole (PPO) was purchased from Acros or Sigma-Aldrich. All fluorescent molecules were used as received except $p$-vinylbiphenyl, which was purified by silica gel chromatography. The general procedure for plastic scintillator preparation is as follows. In a flamedried round bottom flask filled with argon (Ar), the powders were dissolved in the liquids. The gases were then removed using the freeze-pump-thaw technique, and the solution was carefully transferred into a vial for polymerization. After completion, the vial was broken with a mallet and the scintillator was obtained after polishing the raw material. The contours and back were ultimately covered with $\mathrm{TiO}_{2}$ paint (3 layers, EJ-510 from Eljen Technologies) for better light collection through reflection. The process of preparing these materials has been patented [9].

Pulse shape discrimination was performed by irradiating organic scintillators with an unshielded $\mathrm{AmBe} \approx 0.45 \mathrm{GBq}, \approx 30000 \mathrm{n} / \mathrm{s}$ source. The radioactive source was located $5 \mathrm{~cm}$ away from the scintillator.

Nuclear experiments using the charge comparison method, which allows light component separation, have been performed. Photophysical reasons justifying this method are explained well elsewhere [10]. The experimental set-up is described in Figure 1. A range of plastics and one liquid scintillator are characterized using a Hamamatsu H1949-51 photomultiplier (PMT) for light collection; the anode output is then split three ways. Two of the resulting lines are delayed in time, a key parameter to be tuned, using two NSEC Delay 2058 modules (CANBERRA). The third line is dedicated to triggering a constant fraction discriminator (CFD) 583 (ORTEC) at the incoming signal rate, preceded by a Timing Amplifier 2111 (CANBERRA). The CFD generates a TTL signal, producing a time gate, and its width is also a key parameter requiring optimization. These 3 outputs are plugged into a charge integration device, QDC-VME/CAEN (V465). This device integrates both the total and delayed charges, $\mathrm{Q}_{\text {Tot }}$ and $\mathrm{Q}_{\text {Del }}$, in the time gate.

Light Output (LO) measurements were performed under gamma irradiation using a PMT XP-5500B. Energy spectra are obtained using ${ }^{22} \mathrm{Na},{ }^{60} \mathrm{Co},{ }^{137} \mathrm{Cs}$ and ${ }^{241} \mathrm{Am}$ sources. Their intensities were, respectively, $350 \mathrm{kBq}, 130 \mathrm{kBq}, 400 \mathrm{kBq}$, and $380 \mathrm{kBq}$ on 09/17/2013.

Count Rate (CR) measurements were performed under gamma irradiation. Energy spectra were recorded using ${ }^{22} \mathrm{Na},{ }^{60} \mathrm{Co}$ and ${ }^{137} \mathrm{Cs}$ sources, and their intensities were $9.75 \mathrm{MBq}$ on $11 / 07 / 11,240$ $\mathrm{kBq}$ on $03 / 14 / 00$, and $206 \mathrm{kBq}$ on $03 / 14 / 00$, respectively. 


\section{Results and discussion}

\subsection{Preliminary study with liquid scintillator BC-501A}

98 Table 1 summarizes the main characteristics of the studied scintillators. Based on the information contained in their publications, Brooks' [1] and Zaitseva's [6b] scintillators were reproduced for overall comparison with our own scintillators. Various forms of Brooks' scintillator were prepared, according to the observations and issues stated in the past. Finally, our own scintillators were based on an almost identical strategy, integrating the first fluorophore at the highest possible concentration, but with a specially designed polymer matrix. Several concentrations in various matrices were studied. The PSD of a BC-501A liquid scintillator, with excellent $\mathrm{n} / \gamma$ discrimination [11] efficiency, was also determined to allow an ultimate reference comparison to be made.

\section{INSERT TABLE 1 HERE}

First, neutron/gamma discrimination efficiency in the liquid scintillator BC-501A was determined. Both the delayed and total charges were obtained and are referred to as $\mathrm{Q}_{\text {Del }}$ and $\mathrm{Q}_{\text {Tot }}$, respectively. To compare those charges as a function of the particle's incident energy deposited in the scintillator, energy spectra are presented in Figure 2 with ${ }^{137} \mathrm{Cs}(206 \mathrm{kBq}, 03 / 14 / 2000)$ and ${ }^{22} \mathrm{Na}(9.75 \mathrm{MBq}$, 11/07/2011) gamma sources. Statistics are sufficient for energy calibration since the Compton Edge position has been verified to be located at the same position at higher statistics considering uncertainties.

\section{INSERT FIGURE 2 HERE}

Compton edges (CE) are fitted with Gaussians and identified for both gamma energy $\left(\mathrm{E}_{\gamma}\right)$ peaks from

${ }^{22} \mathrm{Na}$ (at $511 \mathrm{keV}$ and $1275 \mathrm{keV}$ ) and for the peak from ${ }^{137} \mathrm{Cs}$ (at $662 \mathrm{keV}$ ). The Compton edges are defined in Equation 1, where $\vartheta$ is taken at $180^{\circ}$, when gamma rays are considered backscattered. CEs are located at $341 \mathrm{keV}$ and $1062 \mathrm{keV}$ for ${ }^{22} \mathrm{Na}$ and at $477 \mathrm{keV}$ for ${ }^{137} \mathrm{Cs}$, as displayed in Table 2 . Compton edges are taken at $80 \%$ of the decay.

Those energies used for the further calibration of the comparison of the charges are obtained in terms of gamma energy; therefore, the calibration is in keVee, standing for $\mathrm{keV}$ electron equivalent. The neutron gamma discrimination spectrum of $\mathrm{BC}-501 \mathrm{~A}$ is presented in Figure 3 where the overlapping region of neutrons and gamma rays at low energy is not visible since a low threshold of 1 is applied to the CFD and induces a cut off in the low energy region. For all energy calibrated spectra presented in this paper, electronics are tuned with the same exact parameters, including the low threshold of the 
134 CFD, for both gamma and neutron/gamma sources acquisitions. In this paper the ratio of the delayed to total charge has been corrected by a factor 1000 for practical data plotting considerations.

INSERT FIGURE 3 HERE

138

140

142

144

\subsection{Optimization of plastic scintillator compositions}

We then decided to reproduce Brooks' Plastic 77 (made from $10 \mathrm{wt} \% 4$-isopropylbiphenyl, $35 \mathrm{~g} \mathrm{~L}^{-1} \mathrm{p}$ terphenyl, and $0.5 \mathrm{~g} \mathrm{~L}^{-1}$ 1,4-Bis(5-phenyl-2-oxazolyl)benzene (POPOP) in polystyrene, as described in Scheme 1) and tried to understand the reasons for its instability in order to achieve a stable composition as shown in Figure 4(a). Indeed, the preparation was rather tedious and scintillators were often non-usable, as presented in Figure 4(b). Ultimately we discovered that annealing the scintillator at a temperature greater than $200^{\circ} \mathrm{C}$ in the final stage could chemically stabilize it, and Sample \#1 was obtained by this method.

INSERT FIGURE 4 HERE

From this experimental procedure, Sample \#1 was prepared in 2007 and has not physically changed since. To further develop this scintillator, increasing the first dye concentration was a priority. Unfortunately, annealing was not efficient for Sample \#3 when doped with $15 \mathrm{wt} \%$ of 4isopropylbiphenyl, and the sample displayed small diffuse white spots after the first week of preparation and became totally white after one month.

\section{INSERT SCHEME 1 HERE}

Based on this observation, we made the assumption that linking the highly concentrated first fluorophore into the polymer matrix would suppress this whitening effect. Replacing 4isopropylbiphenyl with the same amount of 4-vinylbiphenyl led to a stable scintillator, Sample \#4.

The other method for stabilizing the polymer was to create cross-linking between the polymer chains. Thus, an equivalent of Plastic 77 (namely Sample \#5) was prepared by mixing styrene with an appropriate cross-linking agent. Although we feared the scintillation yield would decrease, we obtained a highly transparent and discriminative scintillator.

If the high concentration of 4-isopropylbiphenyl is responsible for the triplet-triplet annihilation, thus allowing $\mathrm{n} / \gamma$ discrimination, the reason for the presence of $p$-terphenyl inside plastic 77 remained unclear. Sample \#2 was thus prepared with no $p$-terphenyl added and, surprisingly, did not display any PSD.

Neutron gamma discrimination spectra for Samples \#1, 2, 4 and 5 are displayed in Figure 6. The 4 samples all have dimensions of approximately $\varnothing 30 \mathrm{~mm} \times \mathrm{h} 10 \mathrm{~mm}$.

\section{INSERT FIGURE 6 HERE}

To determine a given scintillator efficiency, Figures of Merit (FOM) are calculated when projecting the bidimensional (2D) discrimination spectrum at a given energy (keVee), as described in Equation 2, 
where $\mathrm{D}_{\gamma-n}$ is the distance separating neutron and gamma peaks at their projected maxima, and both $\mathrm{L}_{\gamma-}$ FWнм and $\mathrm{L}_{n \text {-FWHм }}$ are the full widths at half maximum of the gamma and neutron peaks. This FOM quantifies neutron and gamma peak separation for PSD assessments.

$182 \quad \mathrm{FOM}=\frac{\mathrm{D}_{\boldsymbol{\gamma}-\mathbf{n}}}{\mathrm{L}_{\boldsymbol{\gamma}-\mathrm{FWHM}}+\mathrm{L}_{\mathrm{n}-\mathrm{FWHM}}}$

Equation 2

Standard deviations of FOM, $\sigma(\mathrm{FOM})$, are determined by propagating uncertainties on each parameter. By considering the error on neutron and gamma peak Gaussian fits, and thus their maxima and half maxima positions, we estimate that the error on each term, $\sigma$, is \pm 1.1 for liquids and 2.1 for plastics because the peaks are closer and the uncertainties on each peak position larger. Therefore, as described in Equation 3, the standard deviation on FOM is calculated as follows:

$\sigma(\mathrm{FOM})=\sqrt{\left(\frac{\boldsymbol{\sigma}}{\left(\mathrm{L}_{\boldsymbol{\gamma}-\mathrm{FWHM}+} \mathrm{L}_{\mathbf{n}-\mathrm{FWHM}}\right)}\right)^{2} \times\left[\mathbf{2}+\mathbf{4} \times\left(\frac{\mathrm{D}_{\boldsymbol{\gamma}-\mathbf{n}}}{\left(\mathrm{L}_{\boldsymbol{\gamma}-\mathrm{FWHM}+} \mathrm{L}_{\mathbf{n}-\mathrm{FWHM}}\right)}\right)^{2}\right]}$

Equation 3

190 The average $\sigma(\mathrm{FOM})$ value is 0.04 for all plastics studied and 0.05 for the $\mathrm{BC}-501 \mathrm{~A}$ liquid scintillator. An example of such projection is given in Figure 7, where a section of the BC-501A 2D spectrum 192 from Figure 3 is displayed at $500 \mathrm{keVee} \pm 10 \%$.

INSERT FIGURE 7 HERE

Projections at $500 \mathrm{keVee}$ from Samples \#1, 2, 4 and 5 are also presented in Figure 8.

As observed in Figures $7 \& 8$, the BC-501A neutron/gamma separation is significantly greater than that observed for Samples \#1, 2, 4 and 5 and is used as an indicator for very good efficiency. Efficiencies were determined through FOM calculations and are presented in Figure 9 and Table 3 for energies from 200 to $500 \mathrm{keVee}$.

\section{INSERT FIGURE 9 HERE}

INSERT TABLE 3 HERE

Sample \#5 is clearly the best preparation among Brooks' compositions where the polymer matrix has been modified. This sample displays an FOM of 0.93 at $300 \mathrm{keVee}$.

\subsection{FOM determination of various lab-made plastic scintillators}

We then examined the potential to use other primary fluorophores. We finally found an appropriate primary fluorophore highly suitable for scintillation and pulse shape discrimination at a very low cost per mol. Thus, various scintillators were prepared containing 1 to $29 \mathrm{wt} \%$ of this primary fluorophore in the matrix. Scintillators doped with concentrations lower than $10 \mathrm{wt} \%$ did not display good $\mathrm{n} / \gamma$ discrimination (data not shown), and the first realistic results were obtained at $17 \mathrm{wt} \%$. This plastic 
scintillator preparation is presented in two different volumes, Sample \#6 (Ø $48 \mathrm{~mm} \times$ h $50 \mathrm{~mm})$ and Sample \#7 (Ø $75 \mathrm{~mm} \times \mathrm{h} 75 \mathrm{~mm})$, in Figure 10 .

\section{INSERT FIGURE 10 HERE}

222

Another sample, Sample \#8, has been prepared using a higher concentration of the first fluorophore (28 wt\%) and a unique dimension of Ø $32 \mathrm{~mm} \times \mathrm{h} 27 \mathrm{~mm}$. Sample \#8 is presented in Figure 11.

INSERT FIGURE 11 HERE

Projections of the neutron/gamma discrimination spectra of Samples \#6 and 7 at $400 \mathrm{keVee}$ are presented in Figure 12, while those of Sample \#8 are shown in Figure 13.

\section{INSERT FIGURE 12 HERE}

INSERT FIGURE 13 HERE

In Figure 14 and Table 4, FOMs that have been calculated are presented for energies between 200 and $900 \mathrm{keVee}$.

INSERT FIGURE 14 HERE

For industrial purposes, it is extremely important to retain the PSD properties while increasing the volume of the scintillator. As one can see, the PSD is only slightly affected; it is reduced by only $\approx$ $30 \%$ at all energies. In Sample \#7, Ø $75 \mathrm{~mm} \times \mathrm{h} 75 \mathrm{~mm}$, neutron/gamma discrimination remains efficient, even at low energy, with an FOM of 0.56 at $300 \mathrm{keVee}$, despite the PMT diameter not being optimized $(50 \mathrm{~mm})$ for such measurements. Sample \#6, equivalent in composition to Sample \#7 but smaller, Ø $48 \mathrm{~mm} \times \mathrm{h} 50 \mathrm{~mm}$, has an FOM of 0.79 at $300 \mathrm{keVee}$. Considering that its size remains significantly large, this plastic is considered very efficient. Going forward, increasing the first dye concentration, as in Sample \#8, causes a FOM increase up to 0.88 at $300 \mathrm{keVee}$, as expected. However, Sample \#8 is smaller, Ø $32 \mathrm{~mm} \times \mathrm{h} 27 \mathrm{~mm}$, and the effect of the concentration increase on PSD efficiency for our composition still needs to be assessed. Additionally, regarding PSD deterioration of Sample \#8 at energies above $500 \mathrm{keVee}$ compared to Sample \#6, this problem has been solved in ongoing work and will be described elsewhere.

Regarding the concentration of the first fluorophore included, it seems that proportional to the volume considered here, the FOM was not significantly increased. However, the study is ongoing and has already yielded an efficient method of greatly optimizing PSD; this will be the subject of our next 256 publication.

\subsection{Comparison with literature data}

As an ultimate characterization of the PSD efficiency of our plastic scintillators, we have remade plastic scintillators based on Zaitseva's preparation [6b] (see Table 1). Resulting samples \#9 and 10, without and with DPA as a secondary fluorophore, respectively, should be more or less equivalent to 
industrial EJ-299-33 [12] in terms of PSD efficiency. Neutron/gamma discrimination spectra from Samples \#9 and 10 are presented in Figure 15.

\section{INSERT FIGURE 15 HERE}

Projections of bidimensional spectra of Samples \#9 and 10 from Figure 15 at $400 \mathrm{keVee}$ are presented in Figure 16, where we can observe that their PSD efficiency appears equivalent.

272 Figures of Merit for Samples \#9 and 10 are presented, and Table 5 provides a comparison with 3 other plastics presented earlier (Samples \#6 and 8 from our preparation at two different concentrations and

274 Sample \#5, corresponding to the best of all Brooks' preparations but in which a modification has been applied to the polymer matrix), allowing an ultimate comparison to be made. We observe that the 276 plastic we have developed, which is still under chemical optimization, already exhibits a PSD efficiency comparable to those reported in the literature.

INSERT TABLE 5 HERE

In Figure 17, we compare Samples \#5, 6, and 8 to Sample \#9, which is based on the preparation reported by Zaitseva et al., which is considered the most efficient of its type. In addition, we have included in Table 6 our data at $480 \mathrm{keVee} \pm 75 \mathrm{keVee}$ to compare to FOM from the EJ-299-33 industrial sample reported in Cester et al. [7].

\section{INSERT FIGURE 17 HERE}

\section{INSERT TABLE 6 HERE}

To add to Figure 17, we note that Zaitseva et al. [6b] characterized their sample under ${ }^{252} \mathrm{Cf}$ irradiation, and that their preparation constitutes the basis of EJ-299-33 and the corresponding samples that we have remade in our laboratory (Samples \#9 and 10). Cester et al. [7] also characterized their commercial sample under ${ }^{252} \mathrm{Cf}$ irradiation; however, in [6b] the source was shielded with $5.1 \mathrm{~cm}$ lead. The sample from [6b] is $\varnothing 25 \mathrm{~mm} \times \mathrm{h} 25 \mathrm{~mm}$, while that tested by Cester et al. is $\varnothing 50 \mathrm{~mm} \times \mathrm{h} 50$ $\mathrm{mm}$ and ours are $\varnothing 32 \mathrm{~mm} \times \mathrm{h} 16 \mathrm{~mm}$.

Zaitseva et al. found FOMs of 2.82 and 3.31 at $480 \pm 75 \mathrm{keVee}$ (without and with DPA, respectively), and while their preparation is comparable to our equivalent samples in terms of volume, energy and, in our opinion, composition, we find FOMs of 1.01and 1.06at $480 \pm 75 \mathrm{keVee}$ for Sample \#9 and 10.

298 However, the FOM calculation method most likely differs, and the shielding of the ${ }^{252} \mathrm{Cf}$ source performed in [6b] may also cause the differences. The nature of the irradiating source, according to some experiments we performed, should not affect FOMs in a significant manner. Additionally, when compared to the FOM results reported by Cester et al., in which a value of 1.29 was found at $480 \pm 75$

$302 \mathrm{keVee}$, the volume is twice as large, which they propose as the source of the discrepancy. Again, in this case [7], the source was unshielded.

304 If we compare all samples from Figure 17 only, Sample \#9 (based on Zaitseva's formulation, PPO 30 wt $\%$ without 9,10-DPA) and Sample \#8 (28.6 wt\% of primary fluorophore with a small amount of 
secondary fluorophore) display relatively stable FOMs on the whole energy spectrum when the same volume is studied.

308 Comparing our recipe, Sample \#6 (17 wt\%), to the same volume of EJ-299-33 (Ø $50 \mathrm{~mm} \times \mathrm{h} 50 \mathrm{~mm}$ ), EJ-299-33's FOM reaches 1.29 , and Sample \#6 0.90 both at $480 \pm 75 \mathrm{keVee}$. Therefore, considering statistical uncertainties, our preparation is $20 \%$ lower in terms of PSD efficiency than EJ-299-33. Higher FOM have been reached in ongoing work that will be presented elsewhere.

\subsection{Light outputs}

314 Sample \#6 and 8, together with a BC-501A liquid scintillator and an EJ-200 plastic scintillator, have been characterized in terms of Light Outputs (LO). LO for commercial samples are as follows:

- EJ-299-33: $8600 \mathrm{ph} / \mathrm{MeV}$ at $1 \mathrm{MeVee}[12]$,

- EJ-200: $10000 \mathrm{ph} / \mathrm{MeV}$ at $1 \mathrm{MeVee}$ (64\% of anthracene) [13],

- $\quad$ BC-501A: $12200 \mathrm{ph} / \mathrm{MeV}$ at $1 \mathrm{MeVee}$ (78\% of anthracene) [14].

LO are provided at $1 \mathrm{MeVee}$, relative to ${ }^{22} \mathrm{Na}$ CE located at $1.062 \mathrm{MeVee}$ (see Table 2); this energy is chosen to allow a comparison with data sheets from commercial scintillators. To obtain the number of photons $/ \mathrm{MeV}$ from the number of phe $/ \mathrm{MeV}$, we divide by the PMT quantum efficiency (QE) as described in Equation 3.

The QE for PMT XP-5500B is 39\%, as described by Swiderski et al. [15]. The estimation of the QE is usually provided with an error of approximately $\pm 10 \%$ to which experimental uncertainty is added, and LO was determined through $80 \%$ of the CEs at $1 \mathrm{MeVee}$. The results from our measurements are comparable to values from the data sheets of BC-501A, EJ-200, and EJ-299-33 and are presented in Table 7. They are comparable because we have tested BC-501A and EJ-200 in the same conditions, then corrected our obtained values according to their data sheets at $1 \mathrm{MeVee}$. We were also able to correct our results so as to be coherent in our overall comparison.

Light Outputs observed for Samples \#6 and 8 from our laboratory are modest in efficiency with values half as good as EJ-299-33; however, improving the LO is part of the ongoing development process.

Count Rate measurements have been performed on a $17 \mathrm{wt} \%$ primary fluorophore $+\varepsilon$ secondary fluorophore plastic scintillator, along with a BC-408 [16] reference plastic scintillator of same size and shape under the same set-up conditions. The results are provided in Table 8 as a percentage relative to BC-408. The relative uncertainties in the results are approximately $10 \%$. The Count Rate was almost identical to the reference, except for ${ }^{22} \mathrm{Na}$, where an unexplained discrepancy is observed.

INSERT TABLE 8 HERE

\subsection{Market considerations}

Potential industrial development of this new type of neutron/gamma discriminating scintillator requires cheap scintillators. As the first fluorophore must be dissolved at a high concentration, typically more than $10 \mathrm{wt} \%$, its price must be as low as possible. For example, the preparation of a 10 $\times 10 \times 10 \mathrm{~cm}^{3}$ cubic scintillator would require no less than $90 \mathrm{~g}$ of compound. Table 9 lists the prices 
of the primary fluorophores used in this manuscript. It seems that our molecule would represent the lowest cost, being 30-fold cheaper than PPO. The most sophisticated fluorophores, 4isopropylbiphenyl and 4-vinylbiphenyl, cannot compete with our molecule in terms of cost.

\section{INSERT TABLE 9 HERE}

356

Ultimately, we were able to produce a monolithic plastic scintillator with huge dimensions. As a proof of concept, a > 1 L sample (Ø $103 \mathrm{~mm}$, length $114 \mathrm{~mm}$ ) was prepared and did not exhibit any physical degradation after almost a year.

\section{INSERT FIGURE 18 HERE}

\section{Conclusion}

This work is divided into two closely related topics. First is the structure/activity relationship of various plastic scintillators which are able to perform a correct PSD between fast neutrons and gamma. In achieving this aim, the fluorophore must meet a number of criteria: absorb and emit light at approximately $300 \mathrm{~nm}$ and $360 \mathrm{~nm}$, respectively, with the best possible photophysical parameters (fluorescence quantum yield, molar absorption coefficient, photobleaching), be highly soluble in nonpolar media (such as styrene) and be stable to radiation. Among the $>50$ formulations tested so far, we were able to produce a good composition of two different fluorophores, a primary and secondary, with the former being added at an optimum concentration of $28.6 \mathrm{wt} \%$. As previously observed, a strong correlation was found between PSD capabilities (in terms of FOM) and the percentage of loading. The potential stability issue was overcome by using cross-linked polymers instead of homopolymers of polystyrene or polyvinyltoluene. Thus, new plastic scintillators with good stability ( $>3$ years so far) have been obtained, with an FOM reaching 1.0 at $480 \pm 75 \mathrm{keVee}$. A proof-of-concept, $>1 \mathrm{~L}$ large scintillator was prepared, showing that our technology is highly reliable, and this technology has the lowest price per gram (overall cost for chemicals $<1 € / g$ ) compared to others on the market. Tested so far to the basic sensor level, PSD-capable plastic scintillators become both the most attractive and affordable technology. With medium-to-long term design integration suitable for portals, this could ultimately open the field to potential replacement of ${ }^{3} \mathrm{He}$.

According to early results from Brooks and recent observations by Zaitseva, different mixtures of fluorophores in a polymer matrix can allow good and fast neutron/gamma discrimination, providing that a high loading of the first fluorophore is performed. This methodology can circumvent the low probability of two triplet states annihilating each other when they are stuck in infinitely viscous solutions. Moreover, our chemical composition is able to stabilize the material (the first samples were prepared in 2007) and enables the production of large plastic scintillators (>1 L) with potentially good PSD and scintillation properties. Light outputs must still be increased. Additionally, many other points must be elucidated, and a complete theoretical understanding of neutron/gamma discrimination in plastic scintillators [10] will be truly appreciated.

\section{Acknowledgments}

Paweł Sibczyński and Joanna Iwanoswka are acknowledged for their extensive help in recording Light Outputs. The Authors are indebted to Canberra for the grant provided to P. Blanc. This work was initiated with the support of the French governmental agency "Agence Nationale de la Recherche" and the NEUTROMANIA program. 


\section{References}

[1] F.D. Brooks, R.W. Pringle, B.L. Funt, IRE Trans. Nuc. Sci. NS-7 (1960) 35.

[2] D.L. Horrocks, Rev. Sci. Instrum. 34 (1963) 1035.

[3] (a) M. Hamel, V. Simic, S. Normand, React. Funct. Polym. 68 (2008) 1671; (b) R. Barillon, E. Bouajila, L. Douce, J.-M. Jung, L. Stuttgé, French Patent Application FR2933699, 2008; (c) N.L. Karavaeva, O.A. Tarasenko, Funct. Mater. 16 (2009) 92; (d) G. O'Bryan, A.L. Vance, S. Mrowka, N. Mascarenhas, Final LDRD Report, Sandia National Laboratories (2010); (e) M. Munier, PhD thesis, University of Strasbourg, 2012; (f) J. Iwanowska, L. Swiderski, M. Moszyński, T. Szczęśniak, P. Sibczyński, N.Z. Galunov, N.L. Karavaeva, JINST 6 (2011) P07007; (g) S. Carturan, A. Quaranta, T. Marchi, F. Gramegna, M. Degerlier, M. Cinausero, V.L. Kravchuk, M. Poggi, Rad. Prot. Dosimetry 143 (2011) 471; (h) M. Dalla Palma, A. Quaranta, T. Marchi, G. Collazuo, S. Carturan, F. Gramegna, M. Cinausero, IEEE proceedings of ANIMMA 2013, (2013).

[4] M.A. Kovash, B. Daub, J. French, V. Henzl, K. Shoniyozov, J.L. Matthews, Z. Miller, H. Yang, IEEE proceedings of ANIMMA 2011 (2012).

[5] (a) G. Corre, V. Kondrasovs, S. Normand, French Patent Application FR2947344, 2009; (b) S. Normand, V. Kondrasovs, G. Corre, J.-M. Bourbotte, A. Ferragut, IEEE proceedings of ANIMMA 2013, (2013); (c) R.R. Hansen, P.L. Reeder, A.J. Peurrung, D.C. Stromswold, IEEE Trans. Nuc. Sci. 47 (2000) 2024.

[6] (a) N. Zaitseva, L. Carman, A. Glenn, S. Hamel, S.A. Payne, B.L. Rupert, PCT Patent Application 2012, WO2012142365; (b) N. Zaitseva, B.L. Rupert, I. Pawelczak, A. Glenn, H.P. Martinez, L. Carman, M. Faust, N. Cherepy, S. Payne, Nucl. Instr. and Meth. A 668 (2012) 88; (c) S. Nyibule, E. Henry, W.U. Schröder, J. Tõke, L. Acosta, L. Auditore, G. Cardella, E. De Filippo, L. Francalanza, S. Gìani, T. Minniti, E. Morgana, E.V. Pagano, S. Pirrone, G. Politi, L. Quattrocchi, F. Rizzo, P. Russotto, A. Trifirò, M. Trimarchi, Nucl. Instr. and Meth. A 728 (2013) 36; (d) S. Pozzi, M. Bourne, S. Clarke, Nucl. Instr. and Meth. A 723 (2013) 19. (e) A. Favalli, M.L. Iliev, K. Chung, C. Hurlbut, H.P. Martinez, M.T. Swinhoe, N.P. Zaitseva, K.D. lanakiev, IEEE Trans. Nuc. Sci. 2013, 2.2, 1053-1056.

[7] D. Cester, G. Nebbia, L. Stevanato, F. Pino, G. Viesti, Nucl. Instr. and Meth. A 735 (2014) 202.

[8] P.L. Feng, J. Villone, K. Hattar, S. Mrowka, B.M. Wong, M.D. Allendorf, F.P. Doty, IEEE Trans. Nuc. Sci. 59 (2012) 3312.

[9] M. Hamel, P. Blanc, C. Dehé-Pittance, S. Normand, French Patent Application 2013, FR1352072.

[10] (a) P. Blanc, M. Hamel, L. Rocha, S. Normand, R. Pansu, IEEE Nuc. Sci. Symp. Conf. Rec. (2012) 1978; (b) M. Hamel, P. Blanc, L. Rocha, S. Normand, R. Pansu, Proc. SPIE 8710 (2013) 87101F.

[11] C. Guerrero, D. Cano-Ott, M. Fernandez-Ordóñez, E. Gonzalez-Romero, T. Martinez, D. Villamarín, Nucl. Instr. and Meth. A 597 (2008) 212.

[12] http://www.eljentechnology.com/index.php/products/plastic-scintillators/114-ej-299-33 (last access February 17 $7^{\text {th }}, 2014$ ).

[13] http://www.eljentechnology.com/index.php/products/plastic-scintillators/48-ej-200 (last access February 17 $7^{\text {th }}, 2014$ ).

[14] http://www.crystals.saint-gobain.com/uploadedFiles/SG-Crystals/Documents/SGC\%20BC501_501A 519\%20Data\%20Sheet.pdf (last access February $\left.17^{\text {th }}, 2014\right)$.

[15] L. Swiderski, M. Moszyński, D. Wolski, T. Batsch, A. Nassalski, A. Syntfeld-Każuch, T. Szczęśniak, F. Kniest, M. Kusner, G. Pausch, J. Stein, W. Klamra, IEEE Nuc. Sci. Symp. Conf. Rec. (2007) 1389.

[16] http://www.crystals.saint-gobain.com/Plastic-Scintillator.aspx (last access February $17^{\text {th }}, 2014$ ). 


\section{Captions}

Figure 1: Experimental set-up of the charge comparison method as PSD method for $\mathrm{n} / \gamma$ discrimination.

Figure 2: ${ }^{22} \mathrm{Na}$ and ${ }^{137} \mathrm{Cs}$ energy spectra from BC-501A liquid scintillator.

Figure 3: BC-501A neutron/gamma discrimination spectrum when exposed to an AmBe neutron source. Neutrons are located in the upper lobe of the graph, whereas gamma rays stand below. (The $\mathrm{Y}$ axis is $\times 10^{3}$ ).

Figure 4: Pictures of three scintillators where only the left one (a) succeeded in preparation process (Sample \#1). All three are $\varnothing 49 \mathrm{~mm}$.

Scheme 1: Drawings of the chemicals.

Figure 5: Picture of Sample \#3 after a month. Diameter is $30 \mathrm{~mm}$.

Figure 6: Plastic Samples \#1,2,4 and 5 respectively (a), (b), (c) and (d) neutron/gamma discrimination spectra when exposed to an AmBe neutron source. Neutrons are located in the upper lobe of the graph, whereas gamma rays stand below for each of the 4 samples presented. (The $\mathrm{Y}$ axis is $\times 10^{3}$ ).

Figure 7: Projection of BC-501A discrimination spectrum at $500 \mathrm{keVee} \pm 10 \%$.

Figure 8: Projections of Samples \#1, 2, 4 and 5 discrimination spectra at $500 \mathrm{keVee} \pm 10 \%$.

Figure 9: Figures of Merit for Samples 1, 2, 4 and 5.

Figure 10: Neutron/gamma discrimination spectra from Samples \#6 and 7 when exposed to an AmBe neutron source from the composition defined in our laboratory at $17 \mathrm{wt} \%$ of first fluorophore. (The $\mathrm{Y}$ axis is $\times 10^{3}$ ).

Figure 11: Neutron/gamma discrimination spectrum from Samples \#8 when exposed to an AmBe neutron source from the composition defined in our laboratory at $28 \mathrm{wt} \%$ of first fluorophore. (The $\mathrm{Y}$ axis is $\times 10^{3}$ ).

Figure 12: Projections of Sample \#6 and 7 discrimination spectra (both at $17 \mathrm{wt} \%$ concentration of first fluorophore) at 400 $\mathrm{keVee} \pm 10 \%$.

Figure 13: Projection of Sample \#8 discrimination spectra (at $28.6 \mathrm{wt} \%$ concentration of first fluorophore) at $400 \mathrm{keVee} \pm$ $10 \%$.

Figure 14: Figures of Merit from Samples \#6, 7 and 8.

Figure 15: Neutron/gamma discrimination spectra from Samples \#9 and 10 when exposed to an AmBe neutron source. (The $\mathrm{Y}$ axis is $\left.\mathrm{x} 10^{3}\right)$. 
Figure 16: Projection of Samples \#9 and 10 discrimination spectra (at $30 \mathrm{wt} \%$ concentration of PPO) at $400 \mathrm{keVee} \pm 10 \%$.

Figure 17: Comparison of the Figures of Merit from 4 samples described in this paper under unshielded AmBe irradiation. Sample \#9, most efficient of Zaitseva mixtures reproduced, Sample \#6 and \#7 two most efficient from our laboratory and Sample \#5 most efficient from Brooks modified mixture.

Figure 18: Picture of Sample \#11 with dimensions $\varnothing 103 \mathrm{~mm} \times \mathrm{h} 114 \mathrm{~mm}$. 


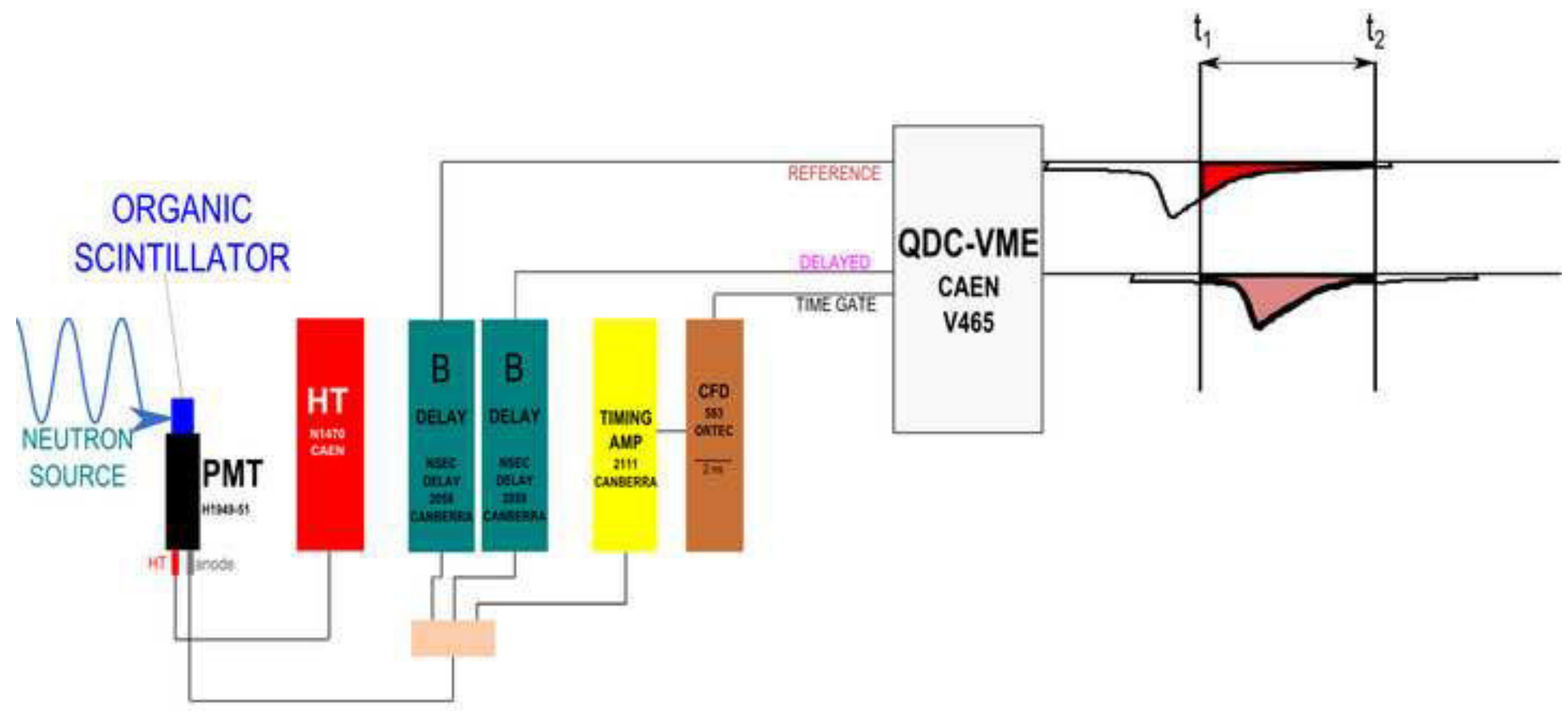




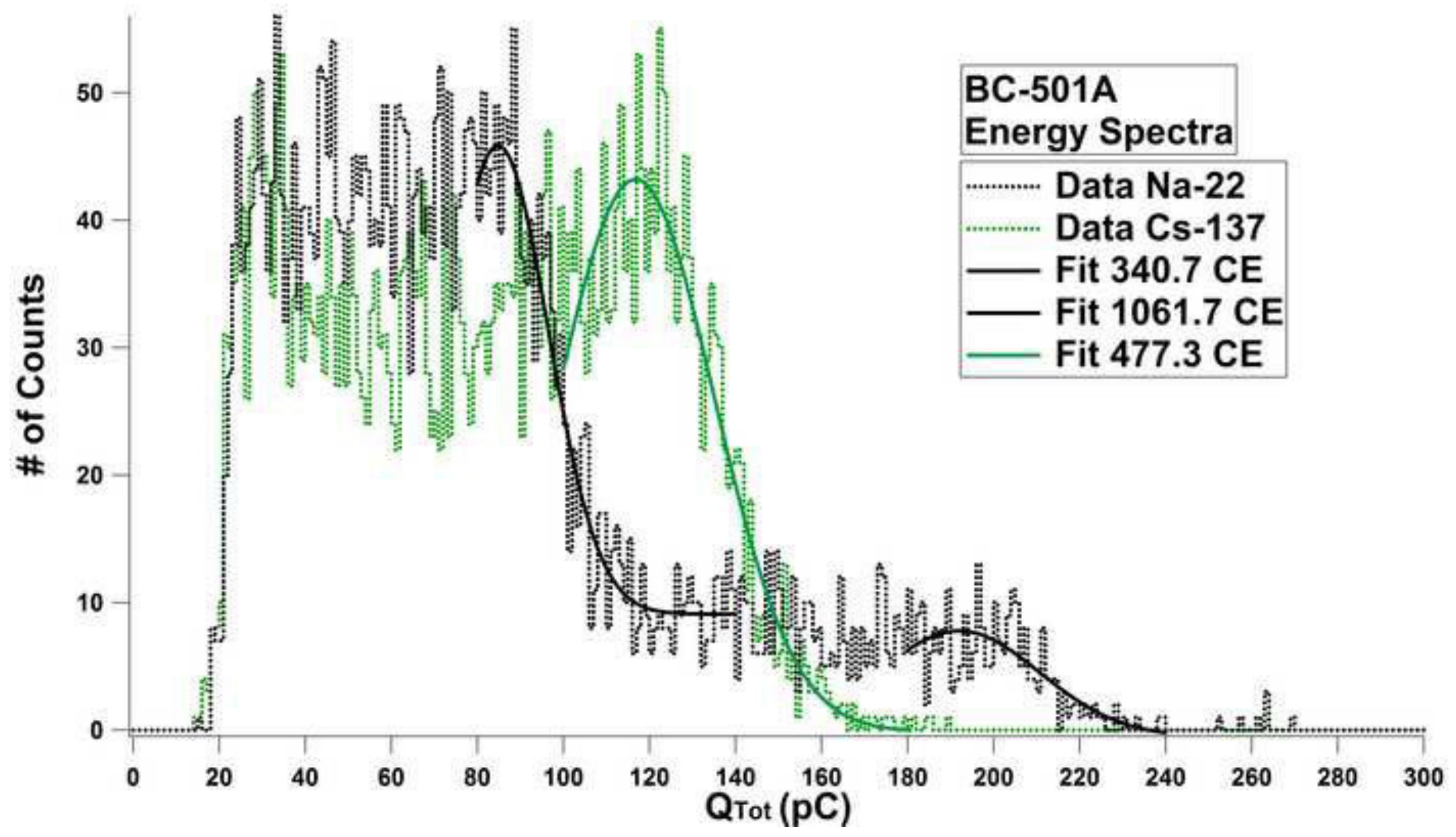


Click here to download high resolution image

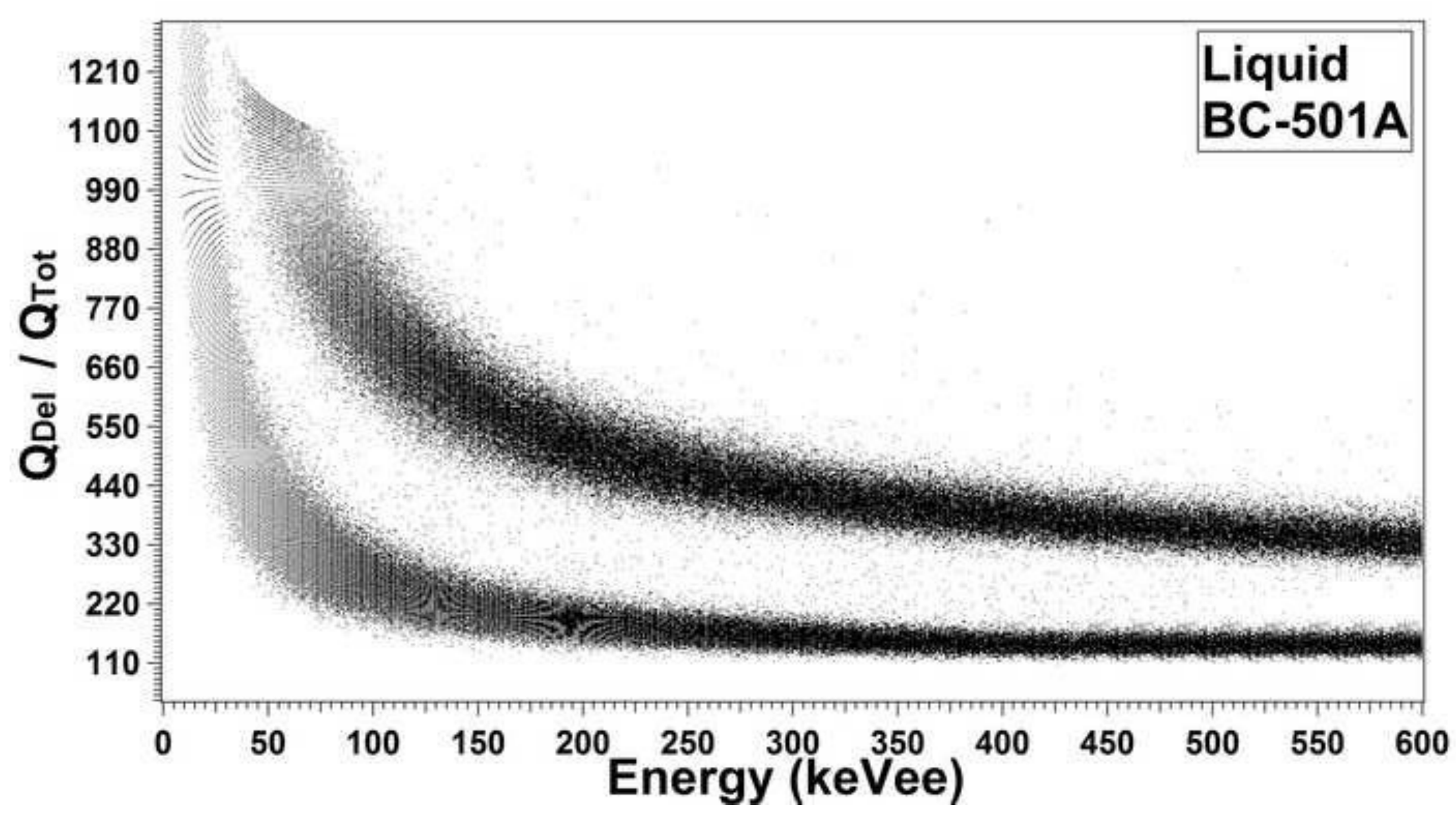


Figure 4
Click here to download high resolution image

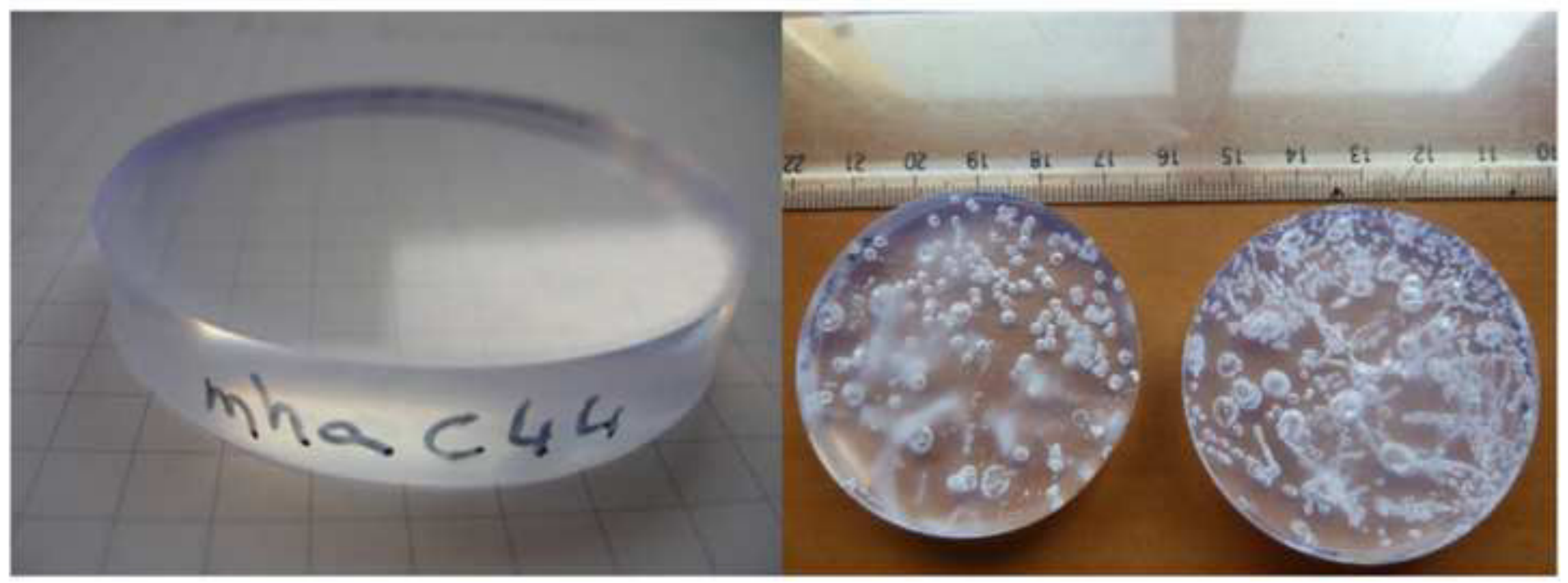


matrix:<smiles>C=Cc1ccccc1C=C</smiles>

styrene vinyltoluene

first fluorophore:<smiles>c1ccc(-c2cnc(-c3ccccc3)o2)cc1</smiles>

PPO

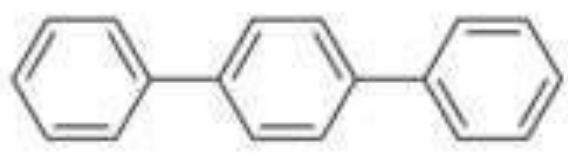

p-terphenyl

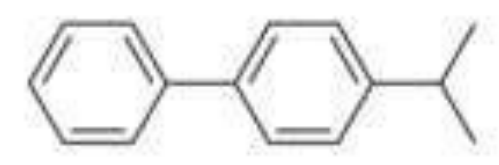

4-isopropylbiphenyl

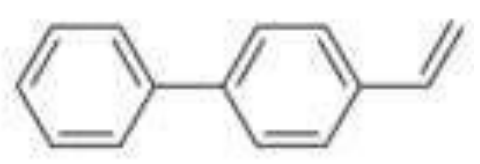

4-vinylbiphenyl

second fluorophore:<smiles>c1ccc(-c2cnc(-c3ccc(-c4ncc(-c5ccccc5)o4)cc3)o2)cc1</smiles>

POPOP

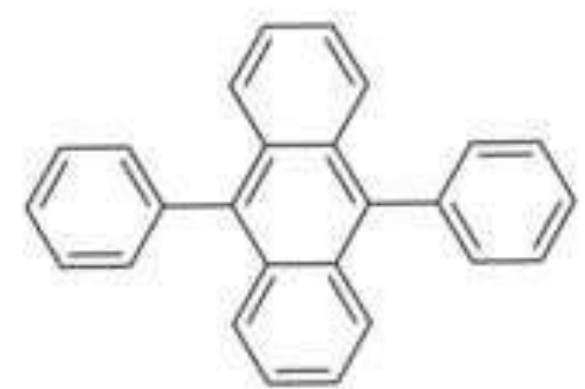

9,10-diphenylanthracene 
Click here to download high resolution image

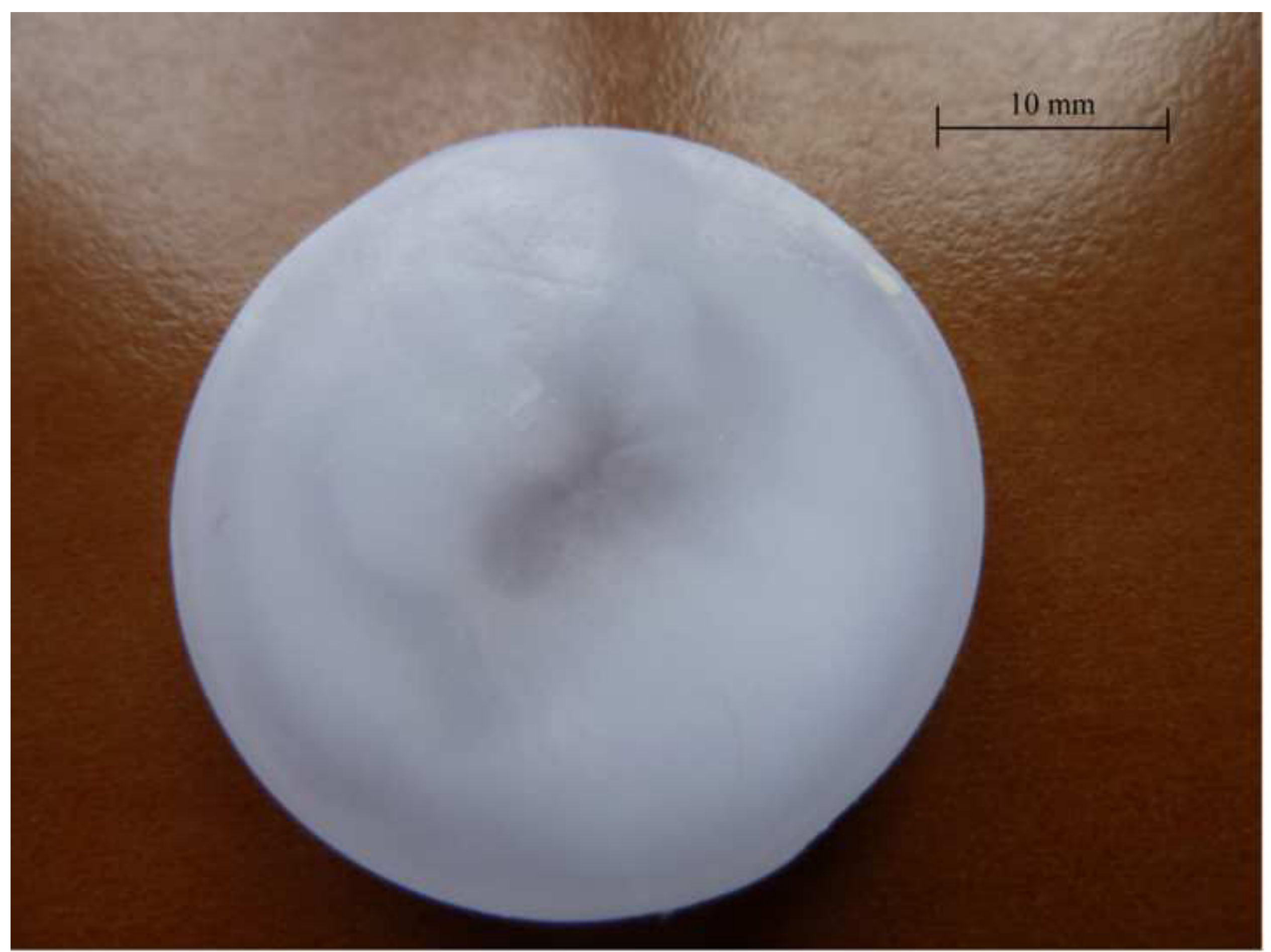


Click here to download high resolution image

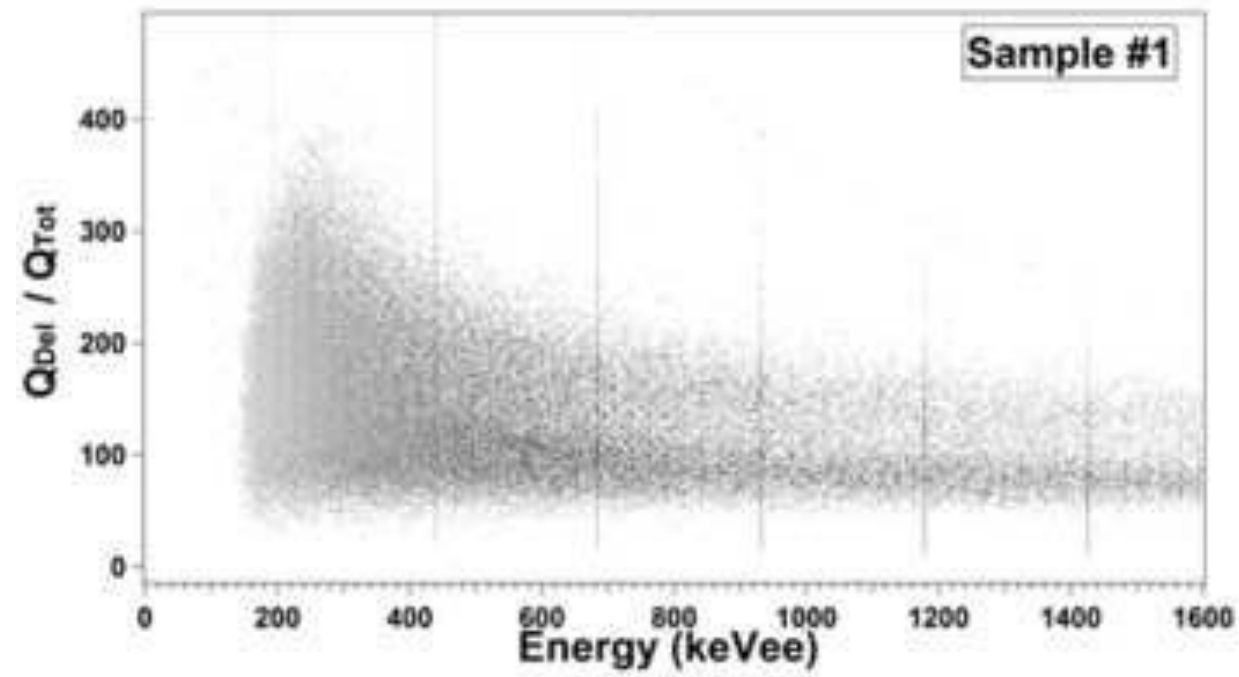

(a)

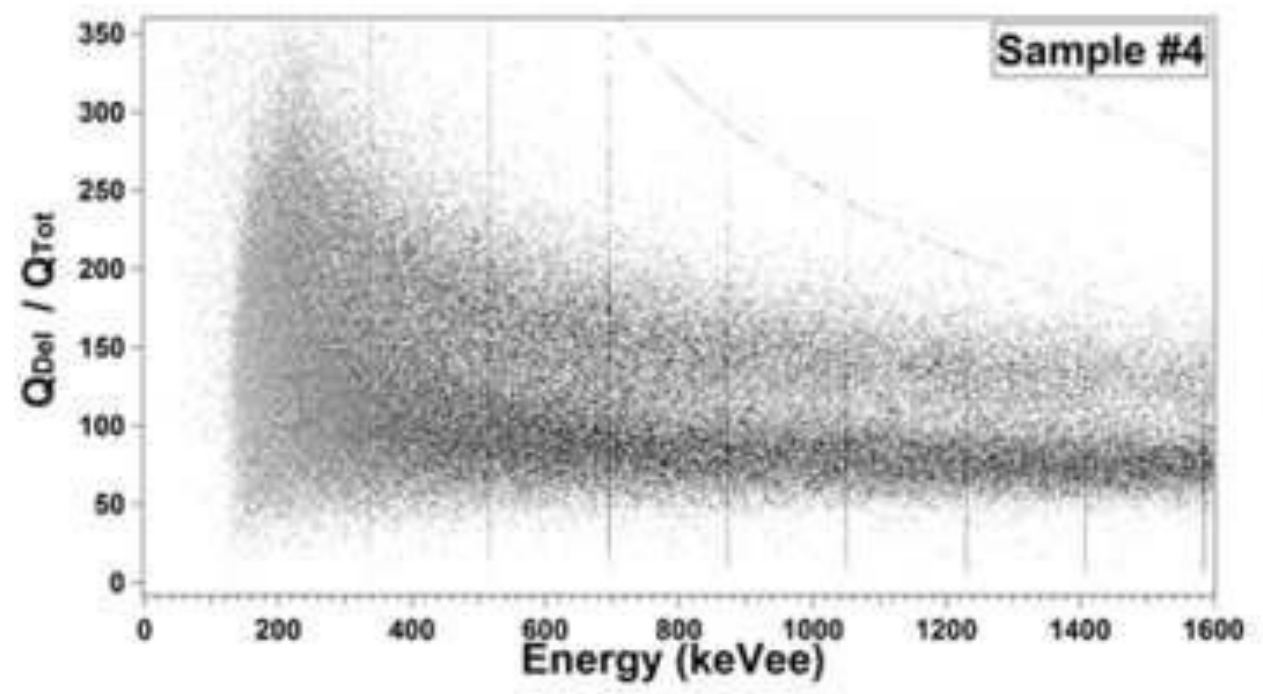

(c)

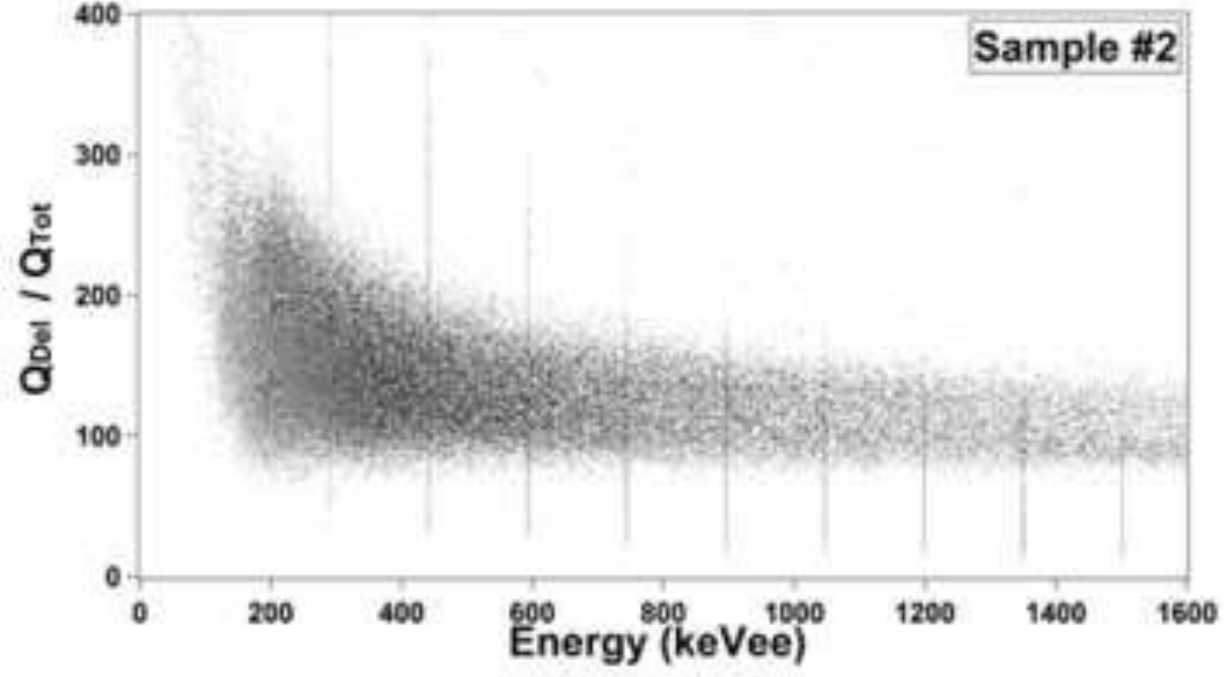

(b)

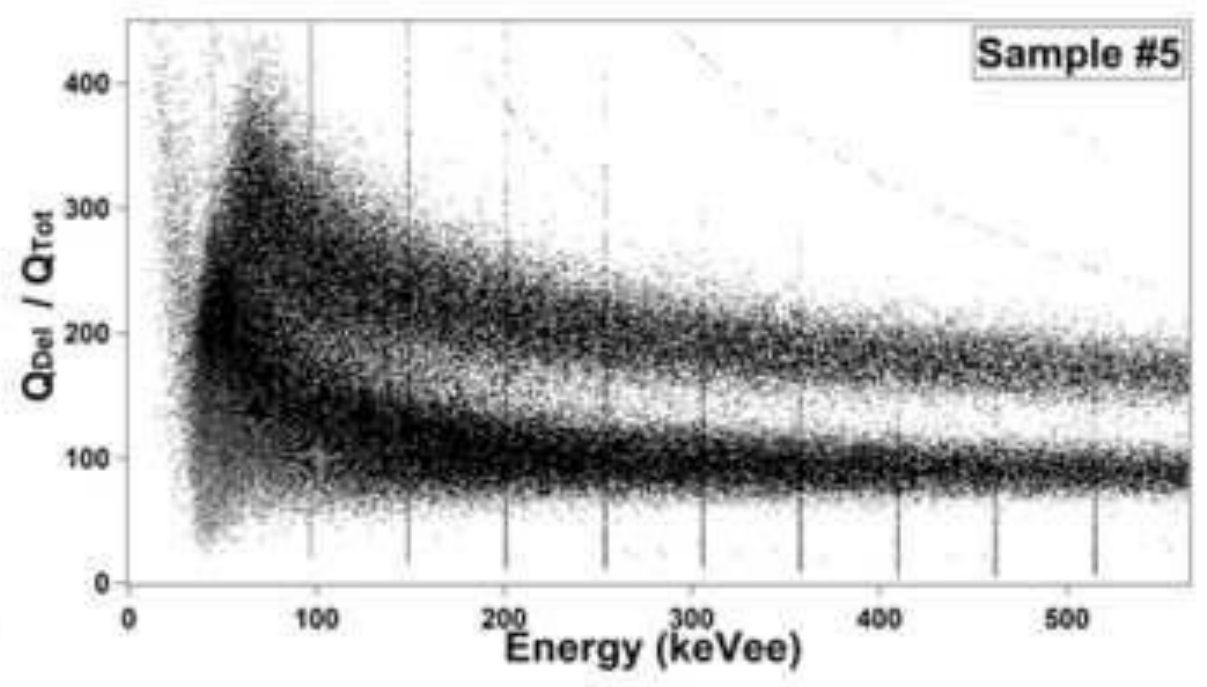

(d) 


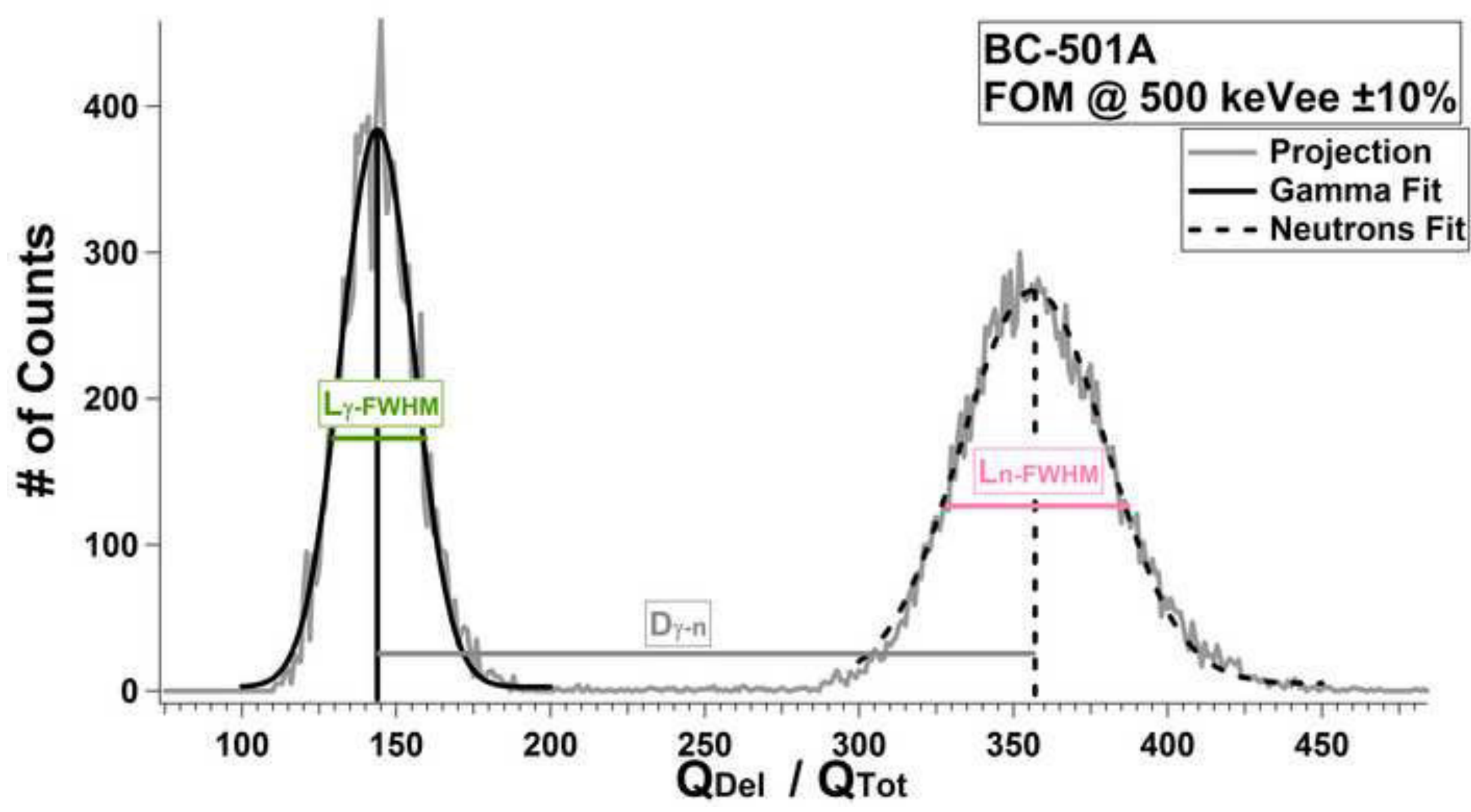


Click here to download high resolution image

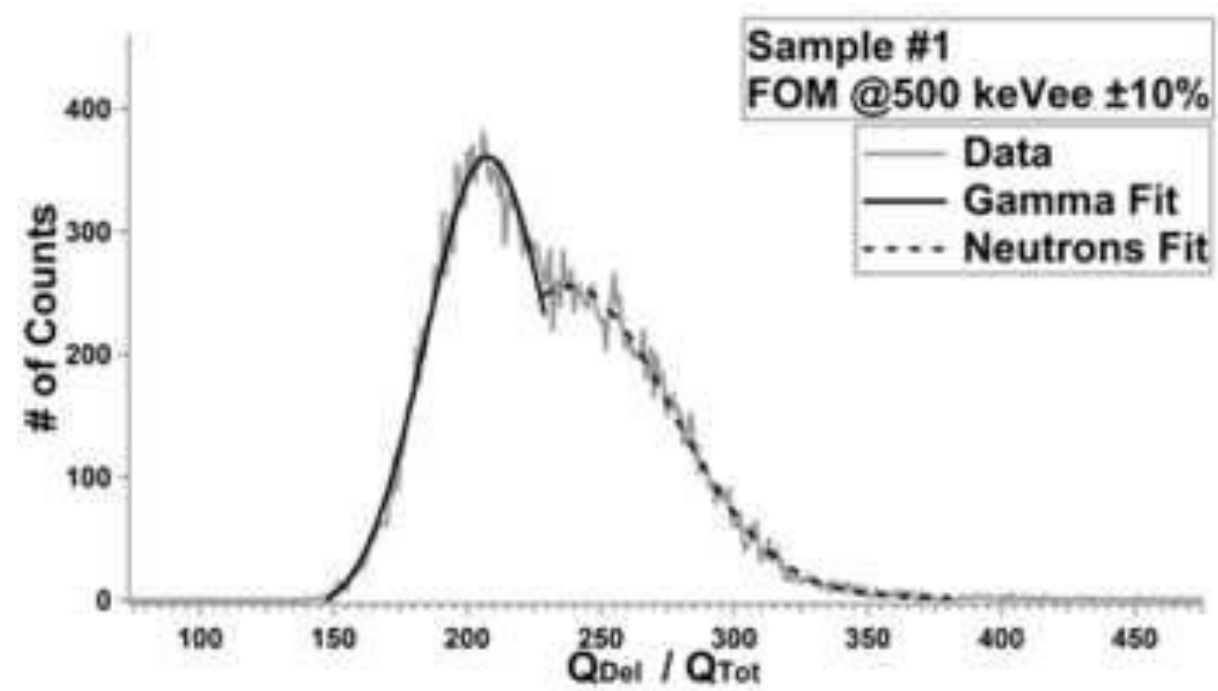

(a)

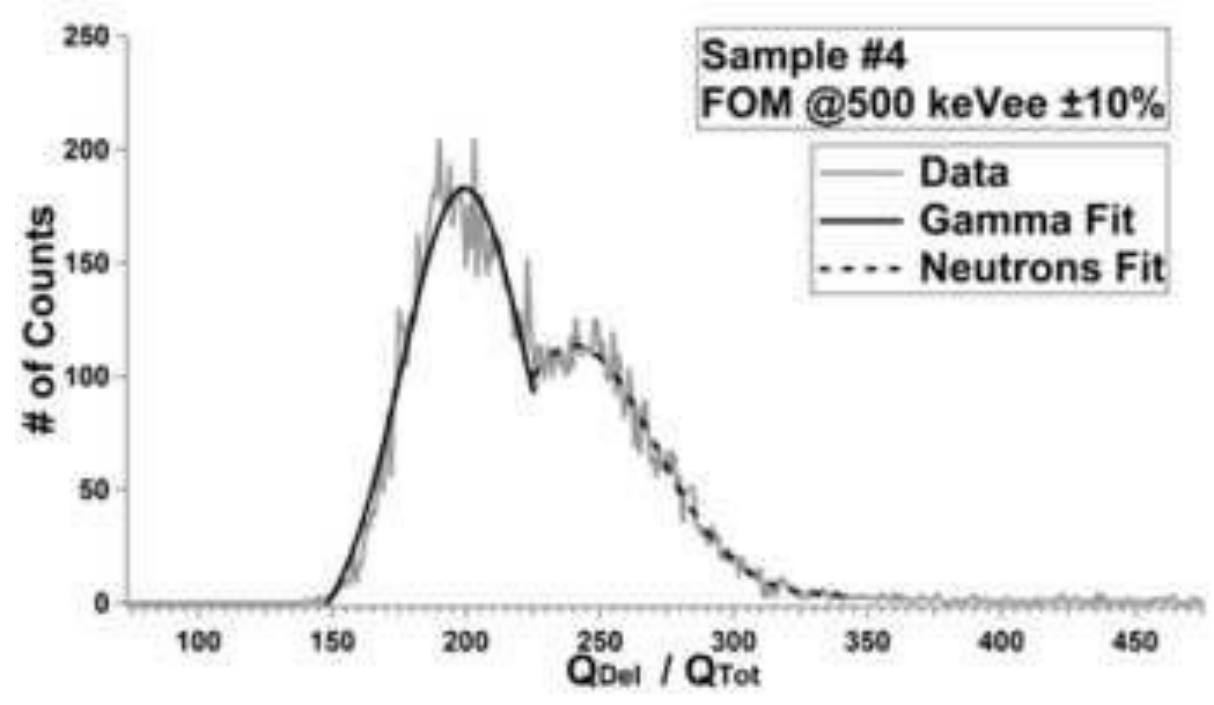

(c)

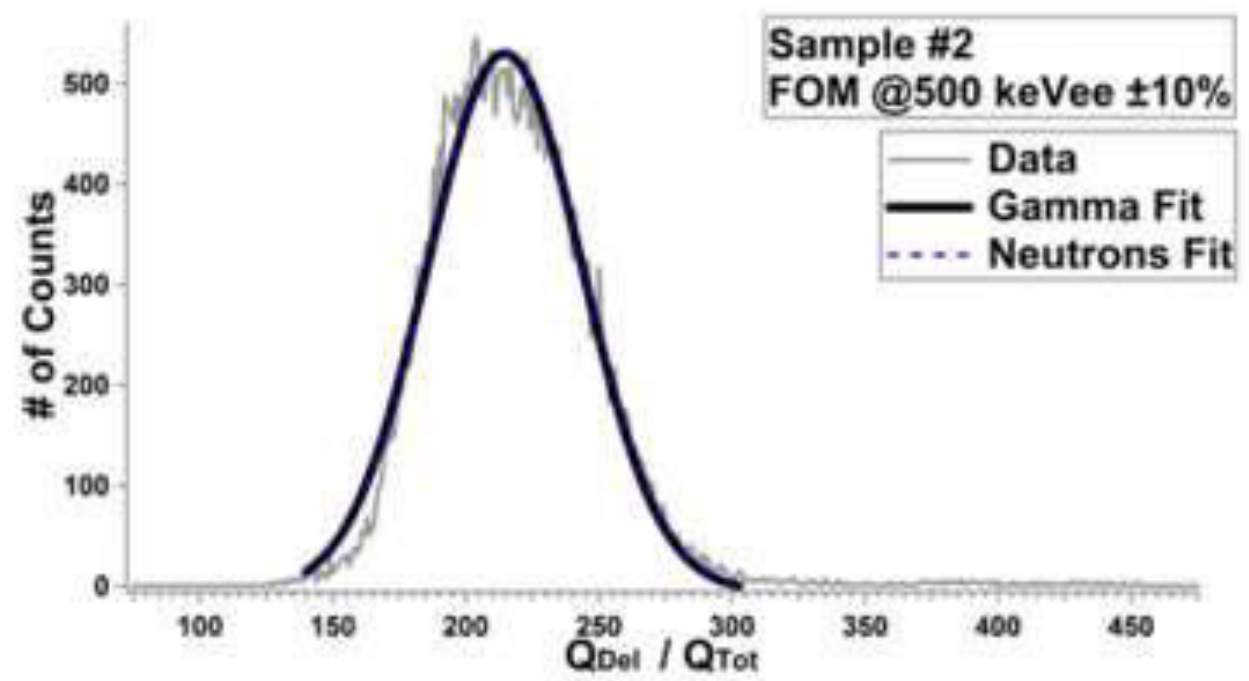

(b)

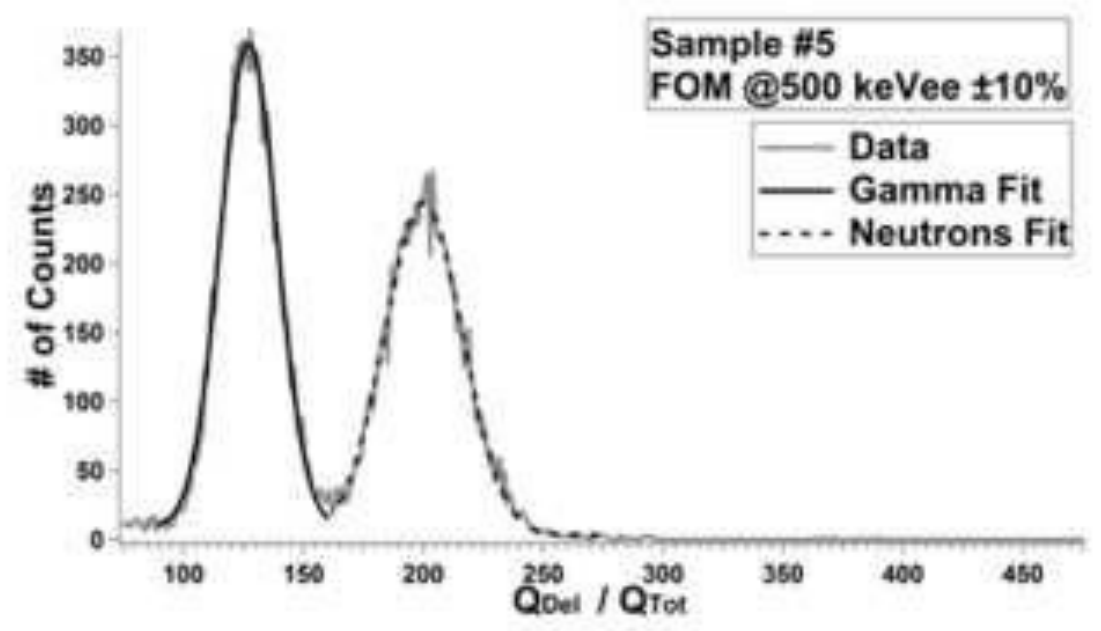

(d) 


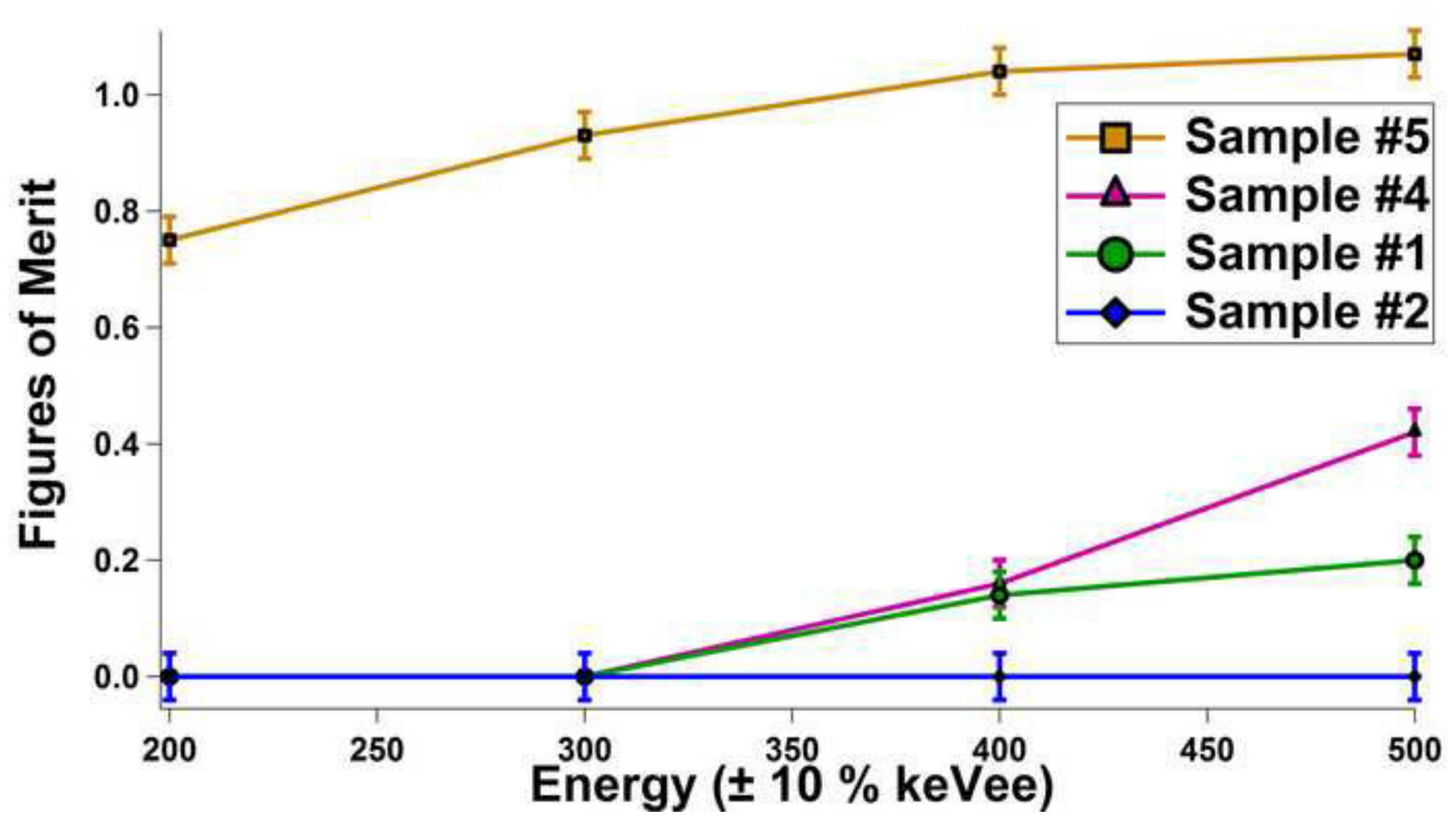


Click here to download high resolution image
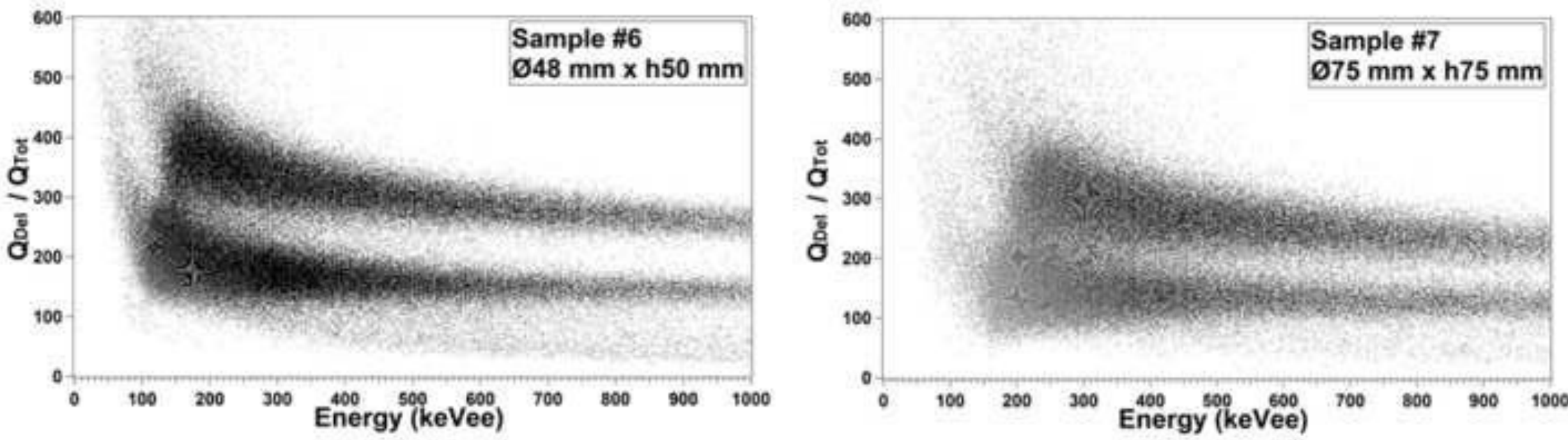

(a)

(b) 


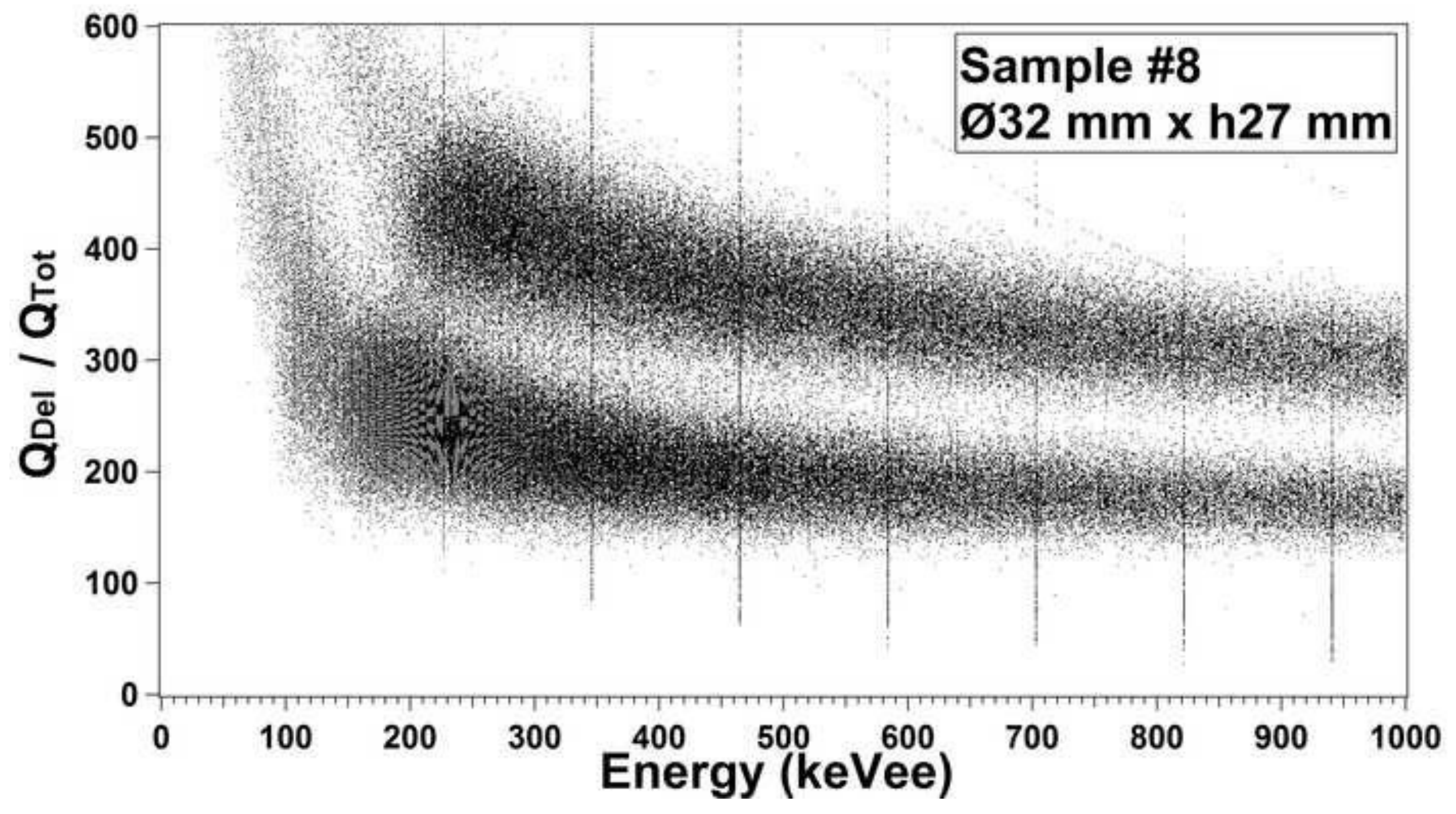




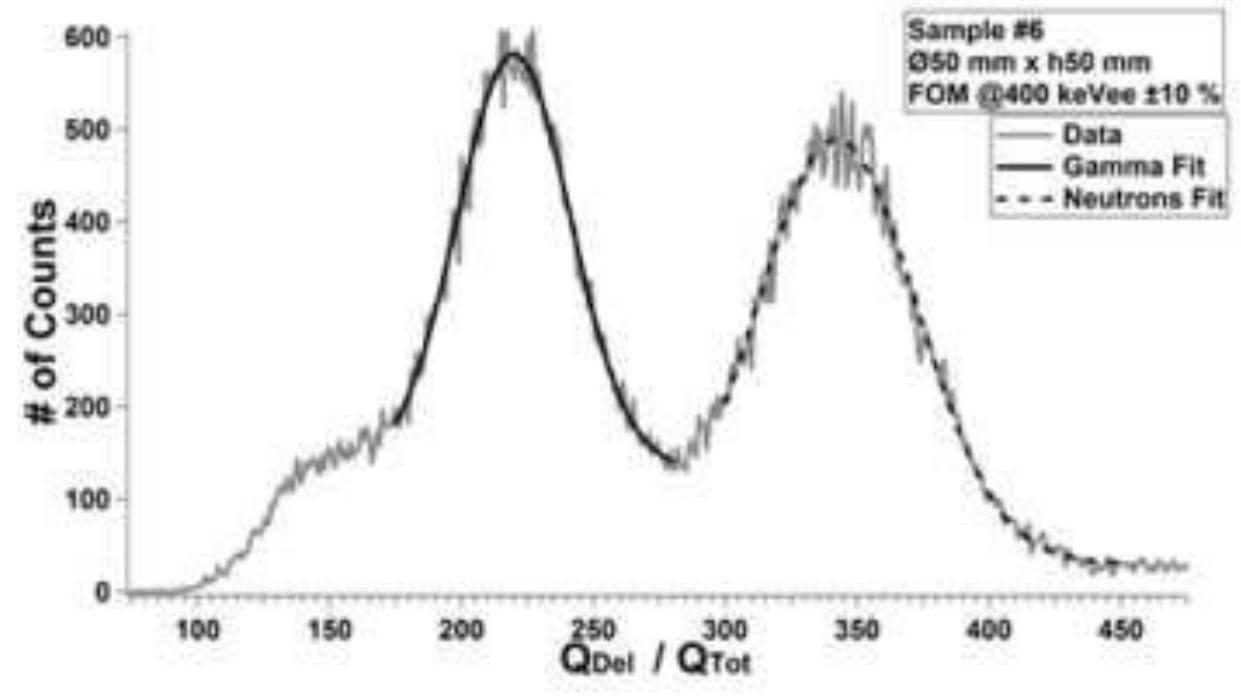

(a)

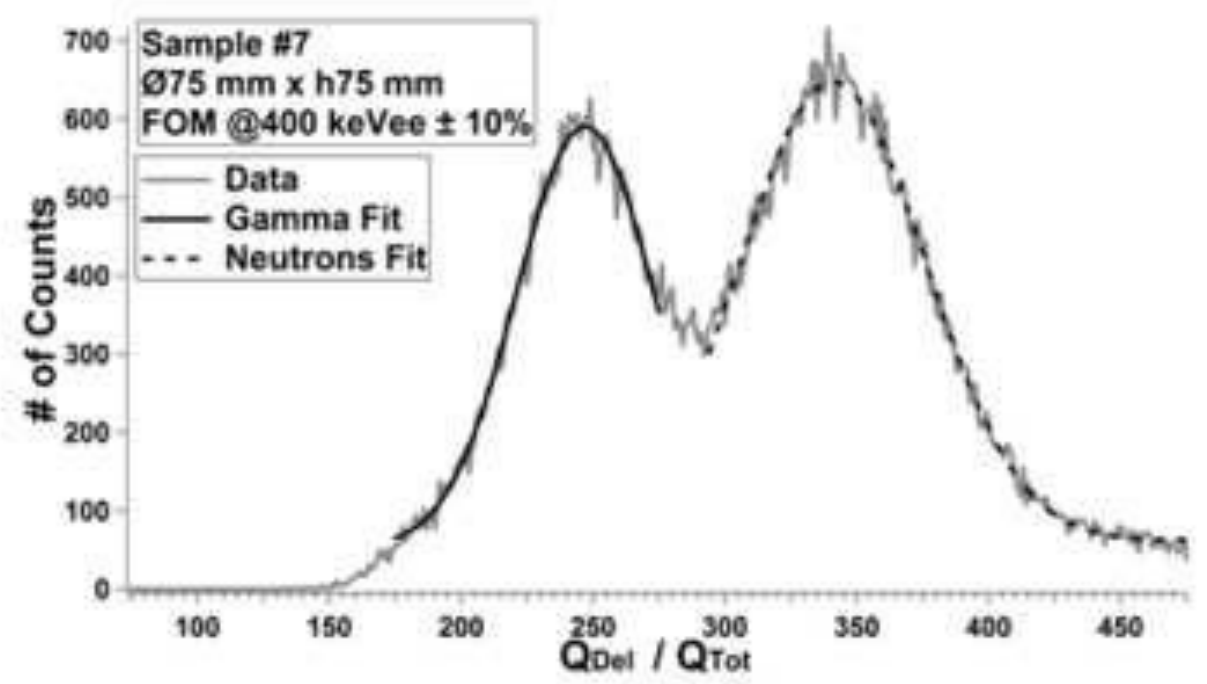

(b) 


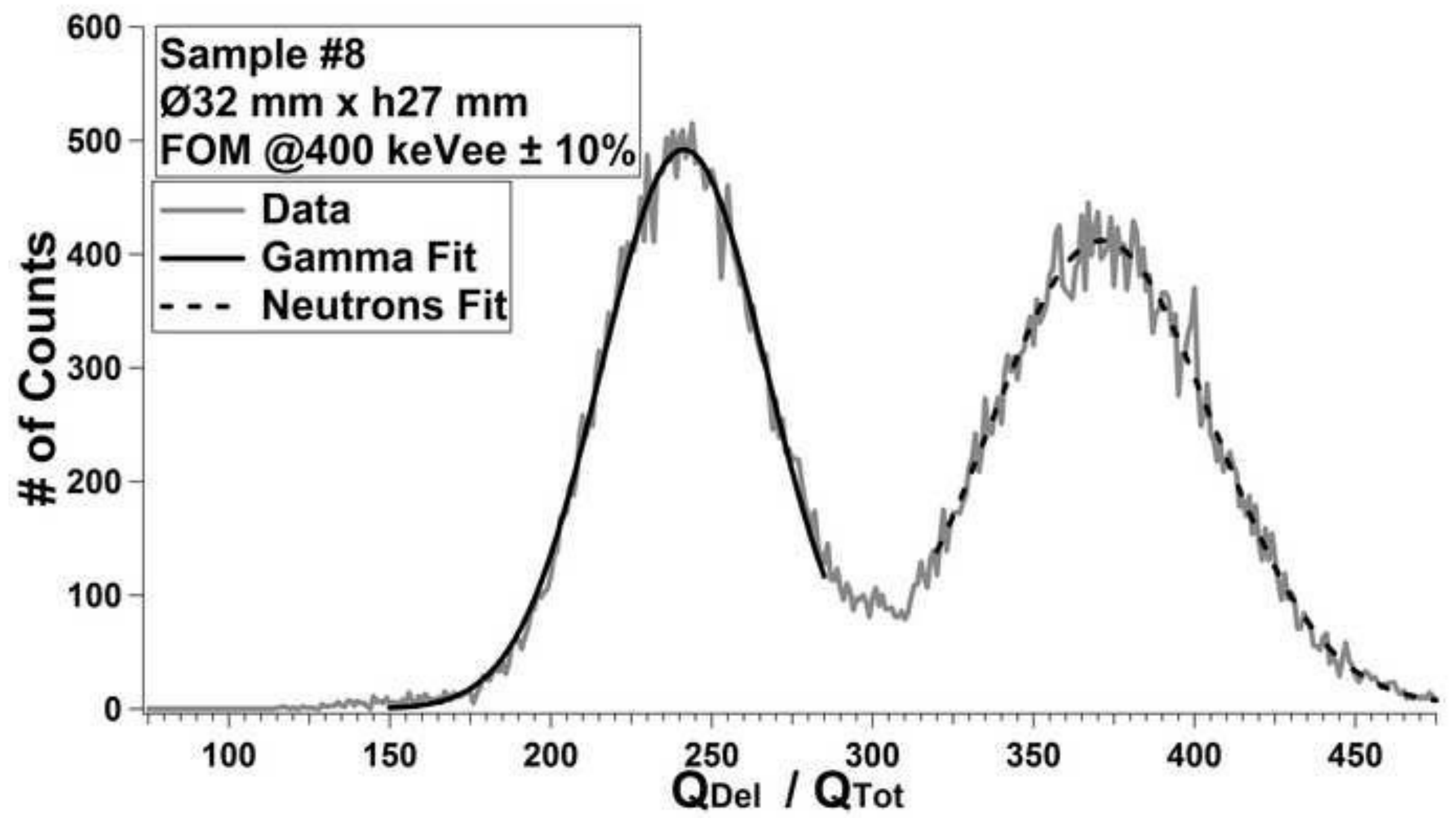




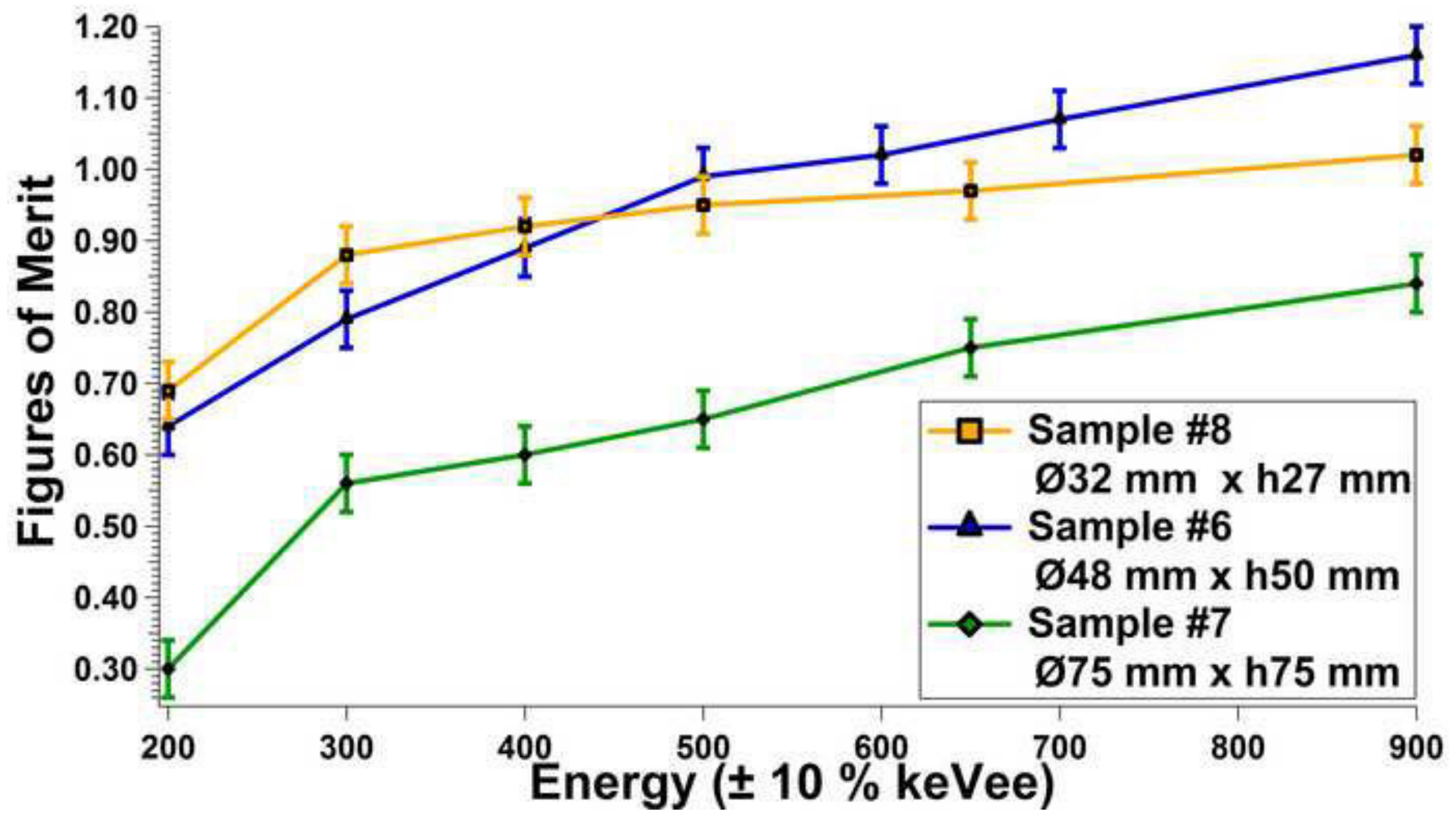


Click here to download high resolution image
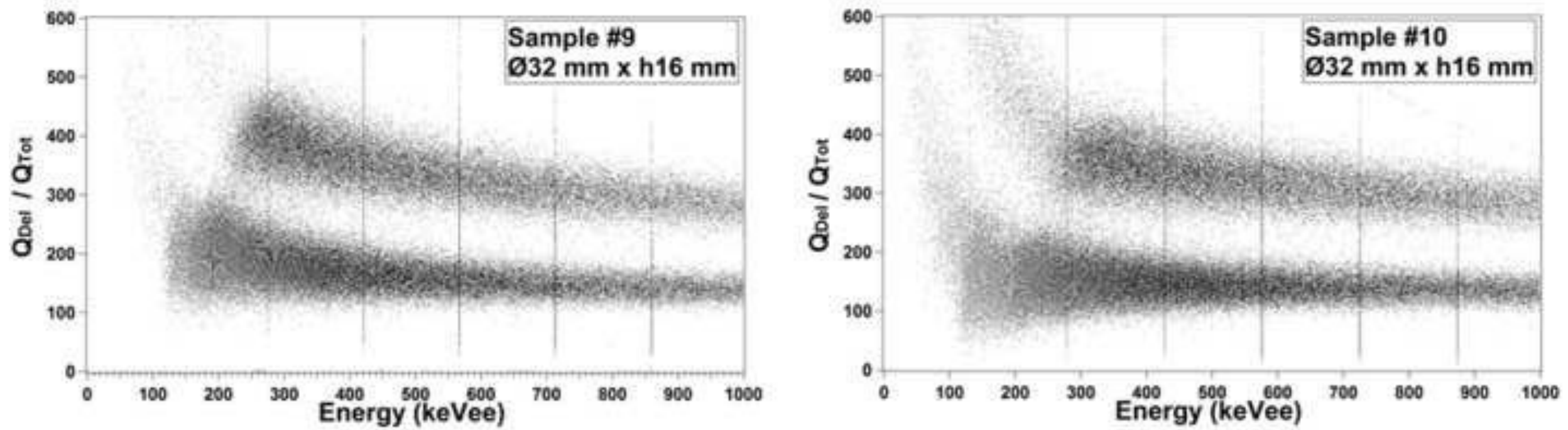

(a)

(b) 

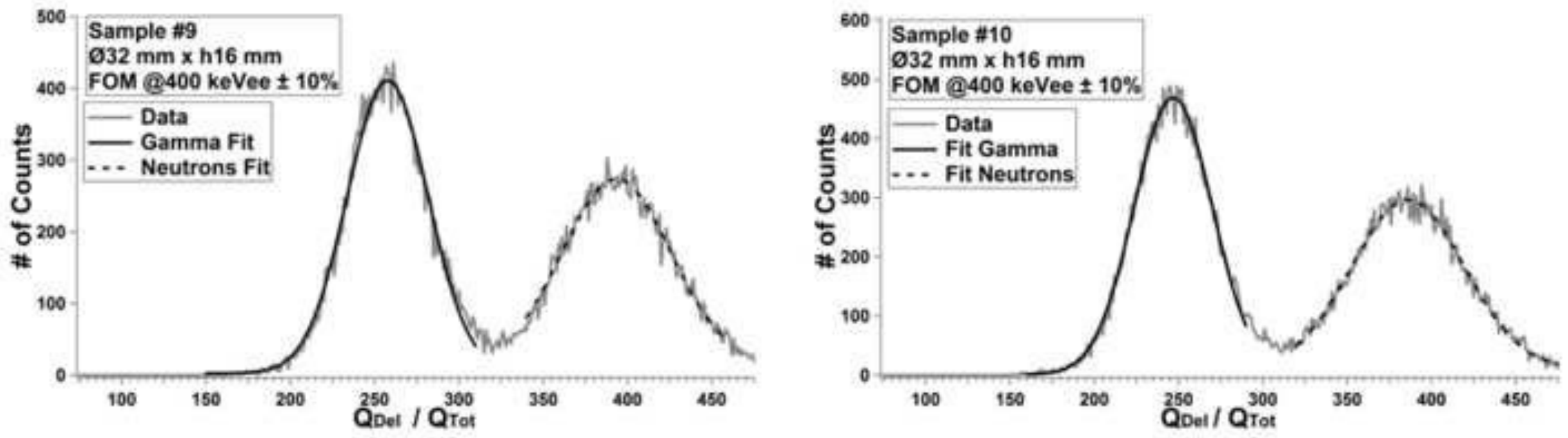

(a)

(b) 


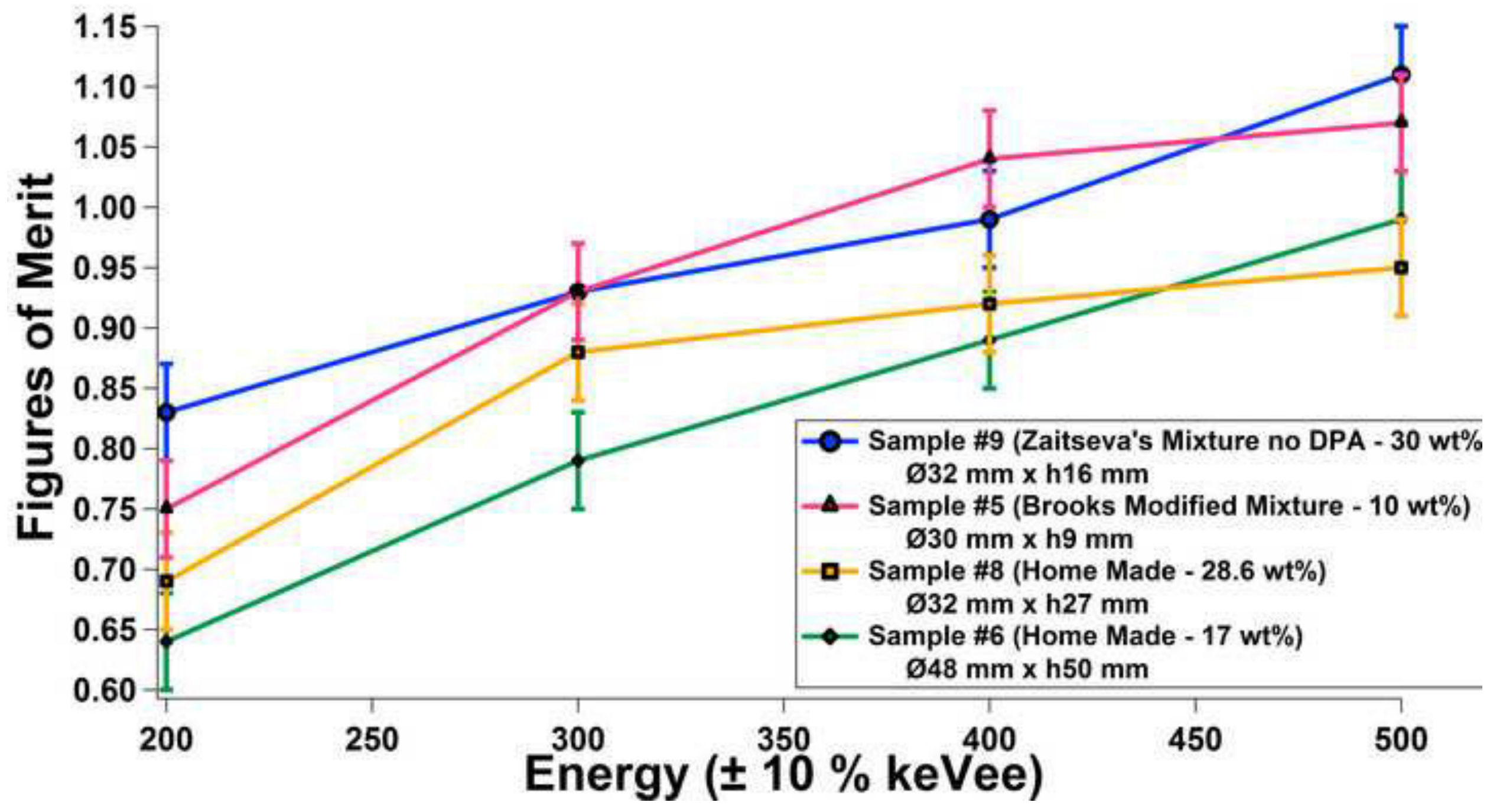


Figure 18

Click here to download high resolution image

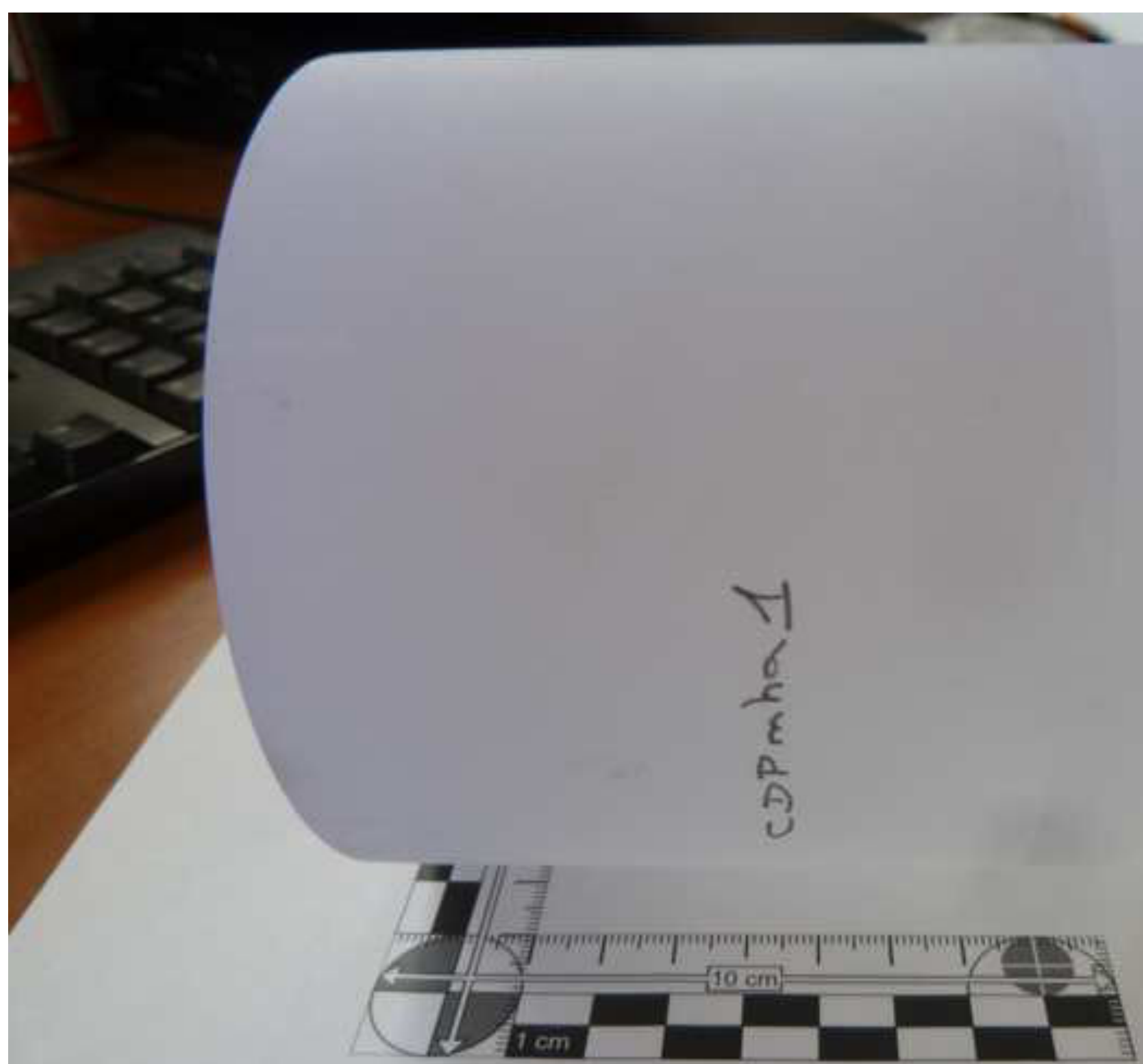


Tables

Table 1: Main characteristics of the various plastic scintillators prepared.

\begin{tabular}{|c|c|c|c|c|c|}
\hline Sample & Dimensi & & $1^{\text {st }}$ fluorophore (wt $\%$ ) & $2^{\text {nd }}$ fluorophore $(\mathrm{wt} \%)$ & Observations \\
\hline & $\begin{array}{l}\text { Diameter } \\
(\mathrm{mm}) \varnothing\end{array}$ & $\begin{array}{l}\text { Thickness } \\
(\mathrm{mm})\end{array}$ & & & \\
\hline$\# 1$ & 49 & 8 & $\begin{array}{l}\text { 4-isopropylbiphenyl (10) } \\
\text { and } p \text {-terphenyl (3.4) }\end{array}$ & POPOP $(0.05)$ & $\begin{array}{l}\text { From Plastic } 77 \text { Brook's } \\
\text { recipe [1] }\end{array}$ \\
\hline$\# 2$ & 30 & 13 & 4-isopropylbiphenyl (10) & POPOP (0.05) & $\begin{array}{l}\text { Equiv. to \#1 without p- } \\
\text { terphenyl }\end{array}$ \\
\hline$\# 3$ & 30 & 5 & $\begin{array}{l}\text { 4-isopropylbiphenyl (15) } \\
\text { and } p \text {-terphenyl (3.4) }\end{array}$ & POPOP $(0.05)$ & $\begin{array}{l}\text { 4-isopropylbiphenyl more } \\
\text { concentrated }\end{array}$ \\
\hline$\# 4$ & 30 & 5 & 4-vinylbiphenyl (10) & POPOP $(0.05)$ & Polymerizable fluorophore \\
\hline$\# 5$ & 30 & 9 & $\begin{array}{l}\text { 4-isopropylbiphenyl (10) } \\
\text { and } p \text {-terphenyl (3.4) }\end{array}$ & POPOP $(0.05)$ & Cross-linked polymer \\
\hline$\# 6$ & 48 & 50 & Proprietary (17) & Yes & Cross-linked polymer \\
\hline$\# 7$ & 75 & 75 & Proprietary (17) & Yes & Identical $\# 6$ but bigger \\
\hline$\# 8$ & 32 & 27 & Proprietary(29) & Yes & Cross-linked polymer \\
\hline$\# 9$ & 32 & 16 & PPO (30) & - & From Zaitseva's recipe [6] \\
\hline$\# 10$ & 32 & 16 & PPO (30) & DPA $(0.2)$ & From Zaitseva's recipe [6] \\
\hline$\# 11$ & 103 & 114 & Proprietary (17) & Yes & Identical \#6 \& 7 but bigger \\
\hline
\end{tabular}

Table 2: Gamma energy and Compton edges of ${ }^{22} \mathrm{Na}$ and ${ }^{137} \mathrm{Cs}$.

\begin{tabular}{ccccc}
\hline Gamma Sources & $\begin{array}{c}\text { Gamma Energies } \mathrm{E}_{\gamma} \\
(\mathrm{keV}) \# 1\end{array}$ & $\begin{array}{c}\text { Gamma Energies }\left(\mathrm{E}_{\gamma}\right) \\
(\mathrm{keV}) \# 2\end{array}$ & $\begin{array}{c}\text { Compton Edges CE } \\
(\mathrm{keV}) \# 1\end{array}$ & $\begin{array}{c}\text { Compton Edges } \\
\mathrm{CE}(\mathrm{keV}) \# 2\end{array}$ \\
\hline${ }^{22} \mathrm{Na}$ & 511 & 1274.5 & 340.7 & 1061.7 \\
\hline${ }^{137} \mathbf{C s}$ & 661.7 & & 477.3 & \\
\hline
\end{tabular}

Table 3: Figures of Merits from Brook's derivative samples compared to BC-501A from 200 to $500 \mathrm{keVee} \pm 10 \%, \sigma \approx \pm 0.05$ for BC-501A and $\sigma \approx \pm 0.04$ for all plastics.

\begin{tabular}{cccccc}
\hline $\begin{array}{c}\text { Energy } \\
(\text { keVee } \pm \mathbf{1 0} \%)\end{array}$ & $\begin{array}{c}\text { Liquid } \\
\text { BC501-A }\end{array}$ & Sample \#1 & Sample \#2 & Sample \#4 & Sample \#5 \\
\hline $\mathbf{2 0 0}$ & 2.11 & 0.00 & 0.00 & 0.00 & 0.75 \\
$\mathbf{3 0 0}$ & 2.31 & 0.00 & 0.00 & 0.00 & 0.93 \\
$\mathbf{4 0 0}$ & 2.52 & 0.14 & 0.00 & 0.16 & 1.04 \\
$\mathbf{5 0 0}$ & 2.53 & 0.20 & 0.00 & 0.42 & 1.07 \\
\hline
\end{tabular}

Table 4: Figures of Merits from Brooks' derivatives samples compared to BC-501A from 200 to $500 \mathrm{keVee} \pm 10 \%, \sigma \approx \pm$ 0.05 for BC-501A and $\sigma \approx \pm 0.04$ for all plastics.

\begin{tabular}{lllll}
\hline $\begin{array}{l}\text { Energy } \\
(\mathbf{k e V e e} \pm \mathbf{1 0} \%)\end{array}$ & $\begin{array}{l}\text { Liquid } \\
\text { BC501-A }\end{array}$ & Sample \#6 & Sample \#7 & Sample \#8 \\
\hline $\mathbf{2 0 0}$ & 2.11 & 0.64 & 0.30 & 0.69 \\
$\mathbf{3 0 0}$ & 2.31 & 0.79 & 0.56 & 0.88 \\
$\mathbf{4 0 0}$ & 2.52 & 0.89 & 0.60 & 0.92 \\
$\mathbf{5 0 0}$ & 2.53 & 0.99 & 0.65 & 0.95 \\
\hline
\end{tabular}

Table 5: Comparison of the Figures of Merit from 4 samples described in this paper. Sample \#9, most efficient of Zaitseva mixture studied, Sample \#6 and \#8 two most efficient from our mixture, Sample \#5 most efficient from Brook's modified mixture, $\sigma \approx \pm 0.05$ for BC-501A and $\sigma \approx \pm 0.04$ for all plastics.

\begin{tabular}{|c|c|c|c|c|c|c|}
\hline Energy $(\mathrm{keVee} \pm 10 \%)$ & Liquid BC501-A & Sample \#9 & Sample \#10 & \multirow{2}{*}{$\begin{array}{c}\text { Sample \#5 } \\
\begin{array}{c}\text { Brook's based } \\
\text { mixture }\end{array} \\
\end{array}$} & Sample \#6 & Sample \#8 \\
\hline & $\begin{array}{c}\text { Liquid } \\
\text { Reference }\end{array}$ & $\begin{array}{r}\text { Zaits } \\
\text { n }\end{array}$ & $\begin{array}{l}\text { based } \\
\text { re }\end{array}$ & & \multicolumn{2}{|c|}{\begin{tabular}{c|c} 
Sample \#6 & Sample \#8 \\
$\begin{array}{c}\text { Lab Made } \\
\text { mixture }\end{array}$
\end{tabular}} \\
\hline 200 & 2.11 & 0.83 & 0.80 & 0.75 & 0.64 & 0.69 \\
\hline 300 & 2.31 & 0.93 & 0.85 & 0.93 & 0.79 & 0.88 \\
\hline 400 & 2.52 & 0.99 & 1.04 & 1.04 & 0.89 & 0.92 \\
\hline 500 & 2.53 & 1.11 & 1.10 & 1.07 & 0.99 & 0.95 \\
\hline
\end{tabular}


Table 6: Summary of FOM values at $480 \mathrm{keVee}$ for EJ-299-33 efficiency comparison.

\begin{tabular}{|l|l|l|l|l|l|l|}
\hline Energy & EJ-299-33 & Sample \#9 & Sample \#10 & Sample \#5 & Sample \#6 & Sample \#8 \\
& Ref [7] & \multicolumn{2}{c|}{$\begin{array}{c}\text { Zaitseva's based } \\
\text { mixture }\end{array}$} & $\begin{array}{c}\text { Brooks' based } \\
\text { mixture }\end{array}$ & \multicolumn{2}{c|}{$\begin{array}{c}\text { Lab Made } \\
\text { mixture }\end{array}$} \\
\hline $480 \pm 75 \mathrm{keVee}$ & 1.29 & 1.01 & 1.06 & 1.04 & 0.90 & 0.91 \\
& \pm 0.04 & \pm 0.04 & \pm 0.04 & \pm 0.04 & \pm 0.04 & \pm 0.04 \\
\hline
\end{tabular}

Table 7: Light Output observed for different liquid and plastic scintillators.

\begin{tabular}{llll}
\hline Organic Scintillator & Observed LO $(\mathbf{p h} / \mathbf{M e V})$ & Corrected LO $($ Lit., $\mathbf{p h} / \mathbf{M e V})$ & Relative approximate Uncertainty \\
\hline EJ-299-33 [12] & n.d. & 8600 & n.d. \\
EJ-200 [13] & 6300 & 10000 & n.d. \\
BC-501A [14] & 7300 & 12200 & n.d. \\
Sample \#6 & 2100 & 3400 & $\pm 20 \%$ \\
Sample \#8 & 2100 & 3400 & $\pm 20 \%$ \\
\hline
\end{tabular}

Table 8: Count Rates from $17 \mathrm{wt} \%$ loaded plastic scintillator normalized to reference BC-408.

\begin{tabular}{lcccl}
\hline Source & ${ }^{22} \mathrm{Na}$ & ${ }^{137} \mathrm{Cs}$ & ${ }^{60} \mathrm{Co}$ & RSD \\
\hline Count Rate (norm. BC-408) & $65 \%$ & $90 \%$ & $95 \%$ & $\pm 10 \%$ \\
\hline
\end{tabular}

Table 9: Prices per mmol for each primary fluorophore.

\begin{tabular}{lllll}
\hline Fluorophore & CAS number & Molecular weight $\left(\mathrm{g} \mathrm{mol}^{-1}\right)$ & Provider & $€ / \mathrm{mmol}$ \\
\hline 4-isopropylbiphenyl & {$[7116-95-2]$} & 196.29 & Alfa Aesar & 4.00 \\
PPO & {$[92-71-7]$} & 221.25 & Acros or S-A & 0.068 \\
4-vinylbiphenyl & {$[2350-89-2]$} & 180.25 & Sigma-Aldrich & 6.20 \\
Proprietary fluorophore & - & - & - & 0.002 \\
\hline Pris
\end{tabular}

Prices concern the product at the higher quantity available, with purity suitable for scintillation purpose, checked on August 29 $9^{\text {th }}, 2012$, without any kind of discount. Considering the same matrix and the same secondary fluorophore, costs relative to them have been discarded. 